\title{
Investigating the Effect of Different Drying Strategies on the Quality Parameters of Daucus carota L. Using Dynamic Process Control and Measurement Techniques
}

\author{
Sharvari Raut $^{1}(\mathbb{D}) \cdot$ Rosalizan Md Saleh $^{1} \cdot$ Phil Kirchhofer $^{1,2} \cdot$ Boris Kulig $^{1} \cdot$ Oliver Hensel $^{1} \cdot$ Barbara Sturm $^{1,3,4}$
}

Received: 7 October 2020 / Accepted: 15 February 2021 / Published online: 21 March 2021

(C) The Author(s) 2021

\begin{abstract}
The present work aims to improve the understanding of the effect of different drying strategies at varying temperatures on the dynamic drying behaviour and quality of organic products such as carrots using non-invasive measurement techniques. For this purpose, carrot slices of $3 \mathrm{~mm}$ thickness were dried under three different strategies namely air temperature controlled (A), product temperature controlled $(\mathrm{P})$ and stepwise temperature controlled (S) at different temperatures $\left(50^{\circ} \mathrm{C}, 60^{\circ} \mathrm{C}\right.$ and $\left.70{ }^{\circ} \mathrm{C}\right)$ to measure and analyse the changes in moisture content, colour, total carotenoid retention, water activity, rehydration ratio and specific energy consumption. From the investigation performed, it was incurred that the application of different drying strategies influences rather significantly both the product quality as well as the overall process efficiency. Modelling the drying curves deemed Page model to be a good fit for all the strategies with $R_{\text {adj }}^{2}=0.99$ and RMSE $=0.01$. The results also show that implementing strategy P not only led to shorter drying times but also led to higher total carotenoid retention within the samples (TCR $=0.59-$ 0.73). Colour changes, however, were observed to be maximum with strategy P as compared to strategy A and strategy S. Furthermore, the use of a non-invasive measurement technique such as infrared camera proved to be reliable in order to detect the phase transition of the product during the drying process.
\end{abstract}

Keywords Drying strategy $\cdot$ Dynamic drying behaviour $\cdot$ Carotenoid retention $\cdot$ Non-invasive measurement

\section{Introduction}

Carrots (Daucus carota L.) are a widely grown root vegetable and ranked sixth most-produced vegetable globally in 2018 (FAOSTAT, 2020). They are considered to be one of the

Sharvari Raut

sharvari.raut@uni-kassel.de

1 Department of Agricultural and Biosystems Engineering, University of Kassel, Nordbahnhofstrasse 1a, 37213 Witzenhausen, Germany

2 Faculty of Process Engineering, Nuremberg Institute of Technology Georg Simon Ohm, Wassertorstraße 10, 90489 Nuremberg, Germany

3 Leibniz Institute for Agricultural Engineering and Bioeconomy (ATB), Max-Eyth Allee 100, 14469 Potsdam, Germany

4 Albrecht Daniel Thaer-Institute of Agricultural and Horticultural Sciences, Humboldt Universität zu Berlin, Hinter der Reinhardtstr. 6-8, 10115 Berlin, Germany healthiest vegetables as they are rich in bioactive compounds like carotenoids and dietary fibres and are also a good source of carbohydrates and minerals such as $\mathrm{Ca}, \mathrm{Fe}, \mathrm{Na}, \mathrm{K}, \mathrm{Mg}, \mathrm{Cu}$, $\mathrm{Zn}$ and vitamin C (Frias et al., 2010; Velescu et al., 2013). However, due to the presence of a high-water content, carrots are susceptible to spoilage which leads to high post-harvest losses and quality degradation.

Food preservation techniques like drying allow for products to be stored for a longer period of time as microbial growth is inhibited in an insufficiently moist environment. Furthermore, enzymes responsible for undesirable changes in chemical compositions e.g. through enzymatic browning also are reduced in their activity (Earle, 1983). In addition to preservation of food quality, the reduction in weight and volume due to drying also reduces the associated packaging, storage and transportation costs (Frias et al., 2010). Of the many methods used for drying, convective air drying is the most economical and commonly implemented method within the food industry (Mujumdar, 2006). An overview of some of the studies conducted through the years using only convective drying technique for carrots is presented in Table 1. 
Table 1 Overview of relevant studies conducted only using convective drying technique

\begin{tabular}{|c|c|c|}
\hline Parameters & Results & References \\
\hline $\begin{array}{l}\text { Mathematical modelling, effective } \\
\text { diffusivities, shrinkage }\end{array}$ & $\begin{array}{l}\text { Shrinkage is an important aspect and cannot be neglected. } \\
\text { Furthermore, to determine the best model, both heat and } \\
\text { mass transfers between the air and the solid needs } \\
\text { to be considered }\end{array}$ & Mulet et al. (1989) \\
\hline $\begin{array}{l}\text { Drying behaviour, mathematical } \\
\text { modelling, effective diffusivity }\end{array}$ & $\begin{array}{l}\text { Effective diffusivity increases with increased air temperature } \\
\text { and velocity. The Page model shows a good fit as compared } \\
\text { to the other models }\end{array}$ & Doymaz (2004) \\
\hline $\begin{array}{l}\text { Drying kinetics, rehydration ratio, } \\
\text { colour and water absorption }\end{array}$ & $\begin{array}{l}\text { Carrot variety plays a significant role in the drying characteristics } \\
\text { and quality parameters }\end{array}$ & Markowski et al. (2006) \\
\hline $\begin{array}{l}\text { Colour, total carotenoid retention, } \\
\text { nonenzymatic browning }\end{array}$ & Blanching prior to drying retains higher $\beta$-carotenoid content & Koca et al. (2007) \\
\hline $\begin{array}{l}\text { Shrinkage, total carotenoid retention, } \\
\text { total polyphenols and antioxidant activity }\end{array}$ & $\begin{array}{l}\text { Temperature affected the degradation kinetics of total carotenoids } \\
\text { and total polyphenols. Optimum drying temperature should be } \\
\text { set based on the quality retention in focus }\end{array}$ & Eim et al. (2013) \\
\hline Degradation kinetics of $\beta$-carotene & $\begin{array}{l}\text { Temperature during drying influences the reaction rate. For better } \\
\beta \text {-carotene retention, drying temperatures of } 44-55^{\circ} \mathrm{C} \text { are suggested }\end{array}$ & Demiray and Tulek (2017) \\
\hline $\begin{array}{l}\text { Drying kinetics, rehydration ratio, } \\
\text { colour }\end{array}$ & $\begin{array}{l}\text { Air temperature and pre-treatment have significant effect on drying } \\
\text { time and quality parameters such as colour }\end{array}$ & Doymaz (2017) \\
\hline $\begin{array}{l}\text { Drying kinetics, total carotenoid retention, } \\
\text { colour, rehydration ratio }\end{array}$ & $\begin{array}{l}\text { Drying characteristics and quality parameters are dependent on } \\
\text { process parameters. Based on statistical optimisation, } 59.8^{\circ} \mathrm{C} \\
\text { is suggested as the optimum drying temperature }\end{array}$ & Md Saleh et al. (2019) \\
\hline $\begin{array}{l}\text { Intermittent drying, colour, carotenoids, } \\
\text { energy consumption }\end{array}$ & $\begin{array}{l}\text { Intermittent drying with tempering results in an increase in product } \\
\text { quality as well as process efficiency }\end{array}$ & Md Saleh et al. (2020) \\
\hline
\end{tabular}

As seen in Table 1 during the drying process, the product undergoes several physical and chemical changes. In the case of carrots, it has been observed that the loss of water causes tensions in the cellular structure that results in a decrease in cell size, roundness and compactness (Kerdpiboon et al., 2007). In terms of phytochemical changes, Lin et al. (1998) observed a decrease in the total carotenoid retention during convective drying for products such as carrot slices. This is because the process of convective drying occurs in two stages (second and third phase of drying) where in the early stages free water moves towards the surface and vaporises. As the process of drying progresses, the liquid within the solid materials becomes more viscous as the concentration of the soluble increases which in turn takes more time for the internal moisture to move towards the surface (Karam et al., 2016) . Furthermore, in the third phase, the physical binding between the solubles is higher, thus elongating the time and energy required for the material to reach the desired moisture content.

The convective drying process is an old process that up until now in industry primarily relies on process and control settings that were established decades ago through trial and error (Mujumdar, 2015). These settings fail to consider or even provide knowledge regarding the relationships between process settings and changes in product characteristics during the process as well as the associated required energy demand (Mujumdar, 2015; Tsotsas \& Mujumdar, 2007-2014). In most cases, isothermal air conditions are assumed and factors such as product temperature are not measured. While the assumption of isothermal air conditions might potentially work for fruits and vegetables, several medicinal plants such as ginseng roots with high initial water content undergo overheating or overdrying (Martynenko \& Kudra, 2015) due to the lack of consideration of non-isothermal behaviour of the product, which in turn reduces the quality of the product. This behaviour could easily be measured through consideration of product temperature.

For holistic optimisation of the drying process, it is important to consider all aspects which includes reduction of quality losses and increase of resource and process efficiency. A study performed by Sturm et al. (2014) indicates that different drying strategies have a significant effect on the product quality and drying time in apple drying. The authors observed that by controlling the product temperature, the process required a shorter drying time with lower colour change in the product. Within Nuñez Vega et al. (2016), the authors introduce a lumped parameter model that simulates constant surface temperature by distinguishing between mass transfer in the liquid and gaseous state. The mathematical model created in this study focuses both on the transport phenomena and the resulting changes in the product (apples). Based on this numerical model, the authors further developed an automatic control feature to simulate the drying process with unsteady process parameters but constant product surface temperature. The study conducted by Nuñez Vega et al. (2016) is an improvement to the models considered for the drying process and evaluates the process-product interaction during the drying process. 
A potential strategy that allows for maintaining product quality as well as being energy efficient is intermittent drying. Intermittent drying allows altering of drying conditions such as air temperature, humidity and pressure over time, thus helping minimise the damage to the product and retain maximum product quality (Kumar et al., 2014). Investigations performed by Pan et al. (1998) showed that intermittent drying preserved $87.2 \%$ of beta carotene in squash as compared to continuous drying which preserved only $61.5 \%$. Quality parameters such a colour change during intermittent drying have also been investigated for food products such as banana (Chua et al., 2001a), guava (Chua et al., 2002) and ginseng root (Davidson et al., 2004)). Studies performed by Chua et al. (2001a) and Chua et al. (2001b) implement a stepwise strategy (one of the strategies of intermittent drying) for the drying process. They present a $40 \%$ reduction in colour degradation for the step-up mode and $23 \%$ reduction for the step-down mode. For ginseng, a three-stage process which includes both step-up and step-down modes was performed by Davidson et al. (2004). The results indicated no significant difference in the $L^{*}$ values when comparing the three-stage process to a lower temperature, but significant colour changes were observed when comparing the stepwise process to a highertemperature drying process. In addition to improving product quality, intermittent drying and its associated strategies have also shown to improve the energy efficiency. Drying is one of the most energy-intensive processes, with about $15-25 \%$ overall global industrial energy demand and efficiencies to the average of 35-45\% (Mujumdar, 2007). Intermittent drying has shown to give energy savings of close to $40 \%$ in the case of $60 \mathrm{~min}$ of tempering period (Chin \& Law, 2010). According to Kumar et al. (2014), increasing the level of intermittency would allow for an increase in energy savings but in turn extend the drying time which could negatively affect the quality of the product. Hence, the authors call for an optimum intermittency level that allows balancing both the quality and energy aspects within the drying process. To this end, $\mathrm{Md}$ Saleh et al. (2019) conducted drying experiments to identify the critical point on the nutritional degradation curve to improve the product quality and extending to process efficiency. The authors identified that for carrots, an inflection point at $30 \%$ moisture content was critical for total carotenoid retention as above this point the beta carotene loss decreased at a low rate and significantly increased below the inflection point. As an extension to this investigation, Md Saleh et al. (2020) also investigated the effect of intermittent drying with information on the inflection point for carrots, and based on the results, the authors conclude that a combination of both these criteria is key for maximum quality retention and process efficiency.

In recent years, the term "smart drying" has gained importance. Smart drying encompasses real-time monitoring of food products and (quasi) real-time adjustment of the process parameters using non-invasive measurement and control techniques. Non-invasive techniques such as computer-aided vision (CAV), thermography (TI), laser backscattering (LB), single-point spectroscopy and hyperspectral imaging (HSI) have shown the ability to analyse the physical and chemical properties, colour, shrinkage, texture, shape, water content, porosity, defects and firmness of the product (Nicolaï et al., 2014). Studies conducted by Martynenko (2006) and Martynenko and Chen (2013) used CCD cameras to measure shrinkage, colour and bulk density for wild blueberries and ginseng, thus paving way for the use of non-invasive techniques for measurement of quality parameters. Sturm et al. (2020) implemented the use of RGB cameras, a VIS-VNIR hyperspectral camera and a pyrometer for dynamic characterisation of hops during the drying process, and results obtained from this investigation show the possibility for novel real-time monitoring of hops during the drying process. A study performed by Huang et al. (2014) proved HSI to be a versatile technology that allows for non-invasive spectral detection of process and product characteristics. They also give a detailed overview regarding the developments in the field of HSI and suggest future work in non-invasive technique such as the use of higher-sensitivity cameras, higher-resolution systems and increasing detection accuracy. Additionally, a study performed by Crichton et al. (2018) reveals that HSI is also suitable for predicting moisture content and moisture content distribution in apples.

Taking this into account, this study aims to understand the effect of different strategies under varying temperatures on the dynamic changes within the product using invasive and non-invasive measurement techniques. The study also investigates the advantages of product temperature-controlled process settings for improved product quality in terms of colour change, rehydration behaviour and retention of total carotenoids. Based on the results obtained by Md Saleh et al. (2019) and Md Saleh et al. (2020), this study further investigates the effect of stepwise temperature-controlled drying rather than intermittent drying to understand the influence on the product quality, process and resource efficiency.

\section{Materials and Methods}

Organic carrots of the variety laguna were obtained from Hessische Staatsdomäne Frankenhausen, a teaching and research facility of the University of Kassel. The freshly harvested carrots were stored at $1{ }^{\circ} \mathrm{C}$ in a cooling chamber until being delivered to the university's laboratory. Once delivered, the carrots were further stored in a refrigerator at $4{ }^{\circ} \mathrm{C}$ (FKUv 1610-22Q, Liebherr-Hausgeräte Ochsenhausen $\mathrm{GmbH}$, Ochsenhausen, Germany) until utilisation for the experiments. 


\section{Sample Preparation}

Carrots were taken out of the refrigerator $30 \mathrm{~min}$ prior to sample preparation and drying so as to acclimatise them to room temperature. The roots were then rinsed under water to remove any excess soil and further sliced to a thickness of $3.0 \mathrm{~mm} \pm 0.1 \mathrm{~mm}$ using a food slicer (EVO E 21, Gebr. Graef GmbH \& Co. KG, Arnsberg, Germany). To ensure a circular shape for each sample, a custom-made stainless-steel cutter of $25.0 \mathrm{~mm} \pm 0.1 \mathrm{~mm}$ in diameter was used. Measurements for sample thickness were carried out using a vernier calliper of an accuracy of \pm $0.02 \mathrm{~mm}$ (model 530-122, Mitutoyo Deutschland GmbH, Neuss, Germany). For repeatability and reproducibility, two roots per experiment were used for drying and further analysis. Figure 1 provides a reference plan for the number of samples used within the experiments. Additionally, the number of samples used within an experiment varied depending on the experimental strategy in focus.

Three repetitions were conducted for each experiment, with the complete experimental procedure being depicted in Fig. 2.

\section{Dryer}

Experimental investigations were performed on a fully automated precision single-layer laboratory-scale dryer which was developed and built at the University of Kassel. A schematic diagram of the system is presented in Fig. 3, and the corresponding details including the model and make of the relevant components are provided in Table 2.

Ambient air enters the system through the inlet fan (V1) and is introduced to the air conditioner via a pipe, where air velocity and temperature are measured using an anemometer (a) which is further connected to a transmitter $\left(a^{*}\right)$. Within the air conditioner, water is sprayed onto a bed packed with random column packing $(R)$ to increase the contact area with the air which passes through the packed bed in counterflow to the water. To achieve consistent relative humidity independent of ambient air conditions, the water bath temperature was set to $20{ }^{\circ} \mathrm{C}$. Prior to establishing this temperature for the water bath, a significant number of pre-tests were conducted to ensure consistent values under varying air temperatures. A class A Pt100 sensor (b) is used to measure and control the temperature of the water bath (W) in the conditioner. The air exiting the conditioner is then heated by the air heaters (H3-H5) to the desired temperature, and the air temperature is further measured by a class A Pt100 sensor (d). Inside the drying chamber, the product is placed on a tray (T) located in the middle of the air stream to ensure that air flows above and beneath the tray. The infrared camera system (e) and the RGB camera system (f) are mounted in a separate chamber above the drying chamber at a distance of $55 \mathrm{~cm}$ and $65 \mathrm{~cm}$ to the tray, respectively. Separation of these two chambers is realised using a plexiglass barrier to provide vision to the cameras while thermally decoupling the instruments to prevent overheating. In the case of the infrared camera, a hole equal to the diameter of the infrared lens was cut into the plexiglass to allow thermography measurement. To dissuade the air from entering the camera chamber while ensuring consistent air flow through the drying chamber, a second ventilator (V2) is synchronised with the inlet ventilator (V1). Process parameters defined for the experimental investigation are provided in Table 3.

The sensors measuring the air velocity (a), air temperature (a) and water bath temperature (b) as well as the infrared camera (e) are connected to the controller module. The controller consists of 4 configurable PID controller channels which were programmed using setup program and in extension the JUMO PCC software

Fig. 1 Sample plan and layout

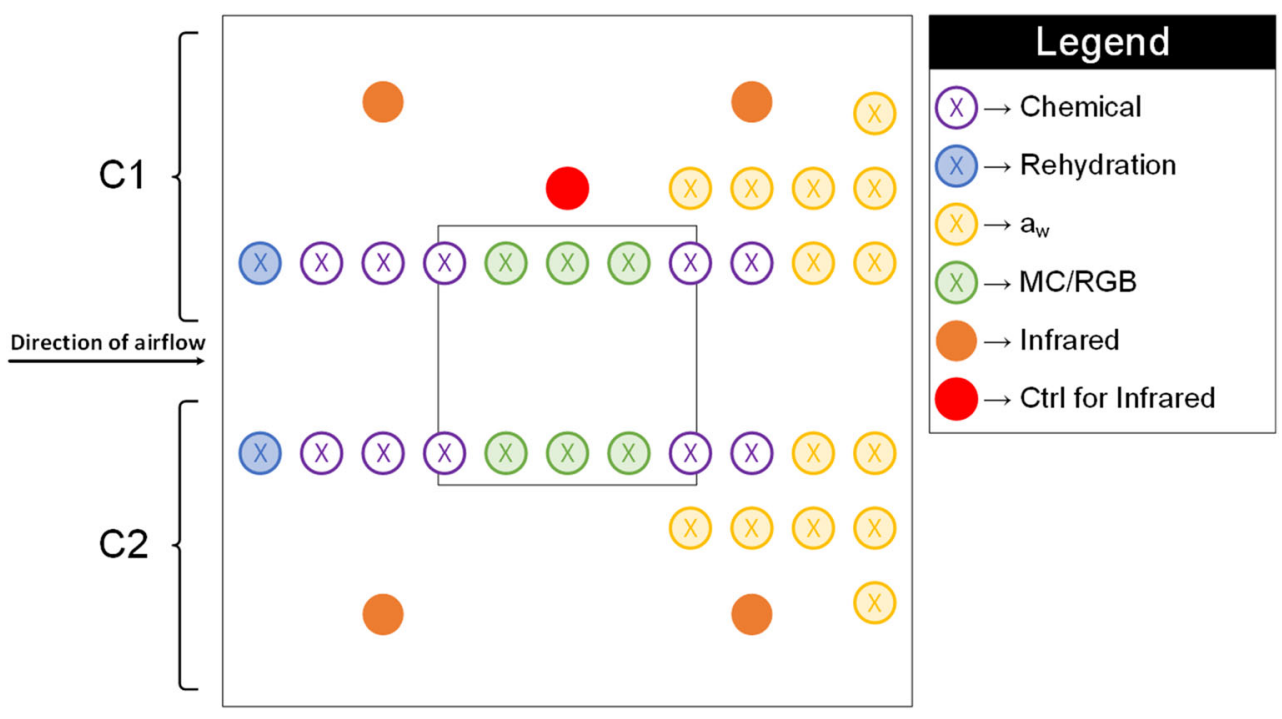


Fig. 2 Experimental procedure for carrot drying

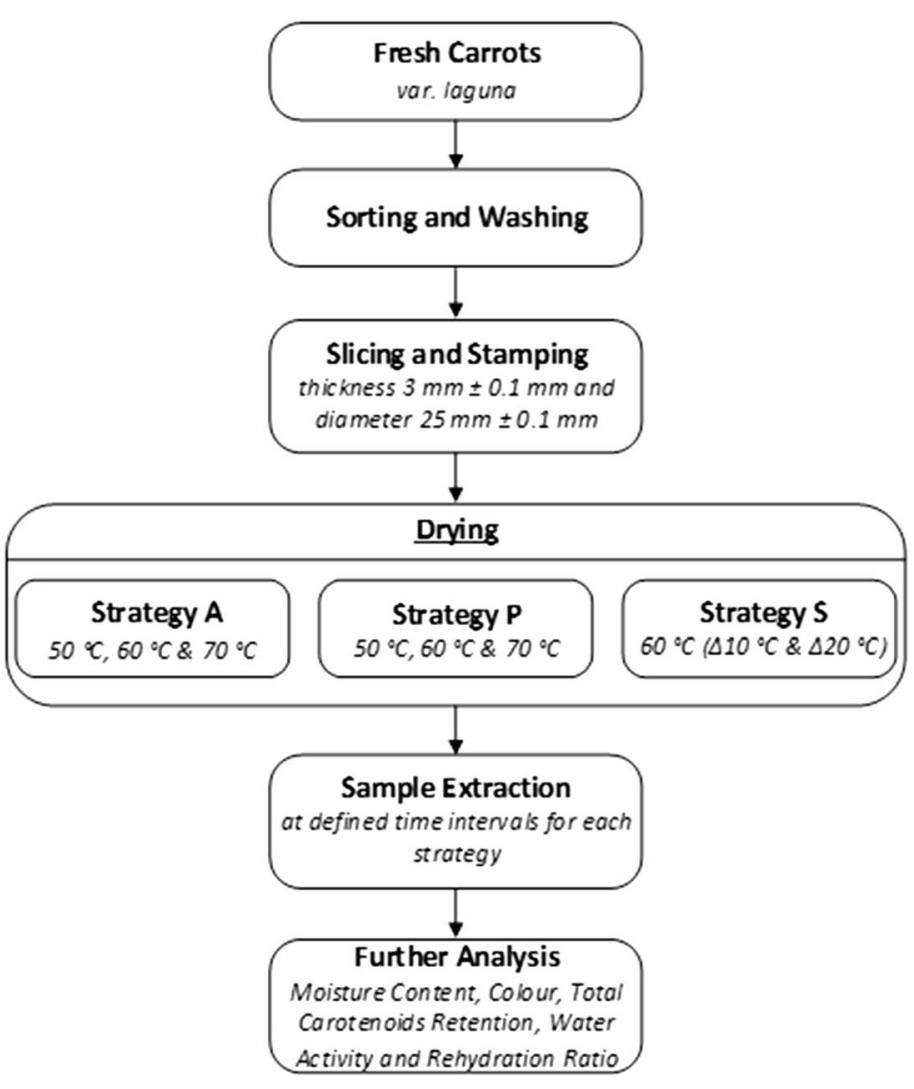

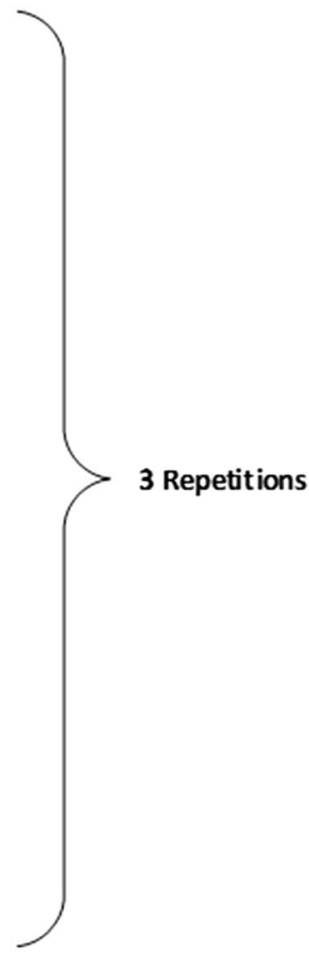

(JUMO GmbH \& Co. KG, Fulda, Germany) to continuously control and adapt the output to the heater within the conditioner and the air heater, respectively.

In this study, three strategies namely air-temperature controlled (A), product-temperature controlled (P) and stepwise temperature controlled (S50/S40) were implemented. For strategy A, the air temperature was held constant throughout the drying process. This is one of the most common strategies used within driers and was conducted at $50^{\circ} \mathrm{C}, 60^{\circ} \mathrm{C}$ and 70 ${ }^{\circ} \mathrm{C}$. As for strategy $\mathrm{P}$, the surface temperature of the product was measured continuously using the infrared camera system (e) which in turn controlled the temperature of air following the principle of the wet and dry bulb temperature. This strategy allows minimising the damage on the product, and reduces thermal load and the overall drying time (Nuñez Vega et al., 2016). Additionally within this strategy, the maximum air temperature was limited to $100^{\circ} \mathrm{C}$ as most industrial dryers for processing of primary agricultural produce rarely operate at temperatures higher than $100{ }^{\circ} \mathrm{C}$ (Sturm, 2010). Like strategy A, this strategy was also conducted for all three temperatures. As for the step-wise temperature-controlled strategies S50 and S40, the goal was to examine the effects of lowering the air temperature at the inflection point identified by Md Saleh et al. (2019) on the colour and total carotenoid retention of the carrots. To this effect, the air temperature was held constant at $60{ }^{\circ} \mathrm{C}$ until the inflection point (30\% MC), which in this study was at $80 \mathrm{~min}$ and thereafter lowering the temperature by either $10{ }^{\circ} \mathrm{C}(\mathrm{S} 50)$ or $20^{\circ} \mathrm{C}(\mathrm{S} 40)$. This strategy unlike the other two strategies was conducted only for 60 ${ }^{\circ} \mathrm{C}$ as this temperature was considered as the baseline control temperature for comparisons to the investigations conducted by Md Saleh et al. (2019).

\section{Colour Measurement}

Both invasive and non-invasive colour measurement techniques were implemented to measure colour changes and further compare and evaluate the difference between the values obtained from the two measurement techniques.

For invasive colour measurement, a calibrated CR-400 Chromameter (Konica Minolta Sensing Europe B.V., München, Germany) in combination with the SpectraMagic NX Software (Konica Minolta Sensing Europe B.V., München, Germany) was used.

For non-invasive measurement, the RGB camera system (g) mentioned in the section "Dryer" in combination with the IC Capture 2.4 Software (The Imaging Source Europe $\mathrm{GmbH}$, Bremen, Germany) was used to control and monitor the acquisition of the images. Images were automatically captured at two min intervals. Illumination for the chamber was provided by three fluorescent lamps (model 92001425, Omnilux®, colour temperature $6400 \mathrm{~K}$ ) with $560 \mathrm{~lm}$ each and placed above the drying chamber to provide uniform illumination and inhibit shadowing. The RGB images thus captured 


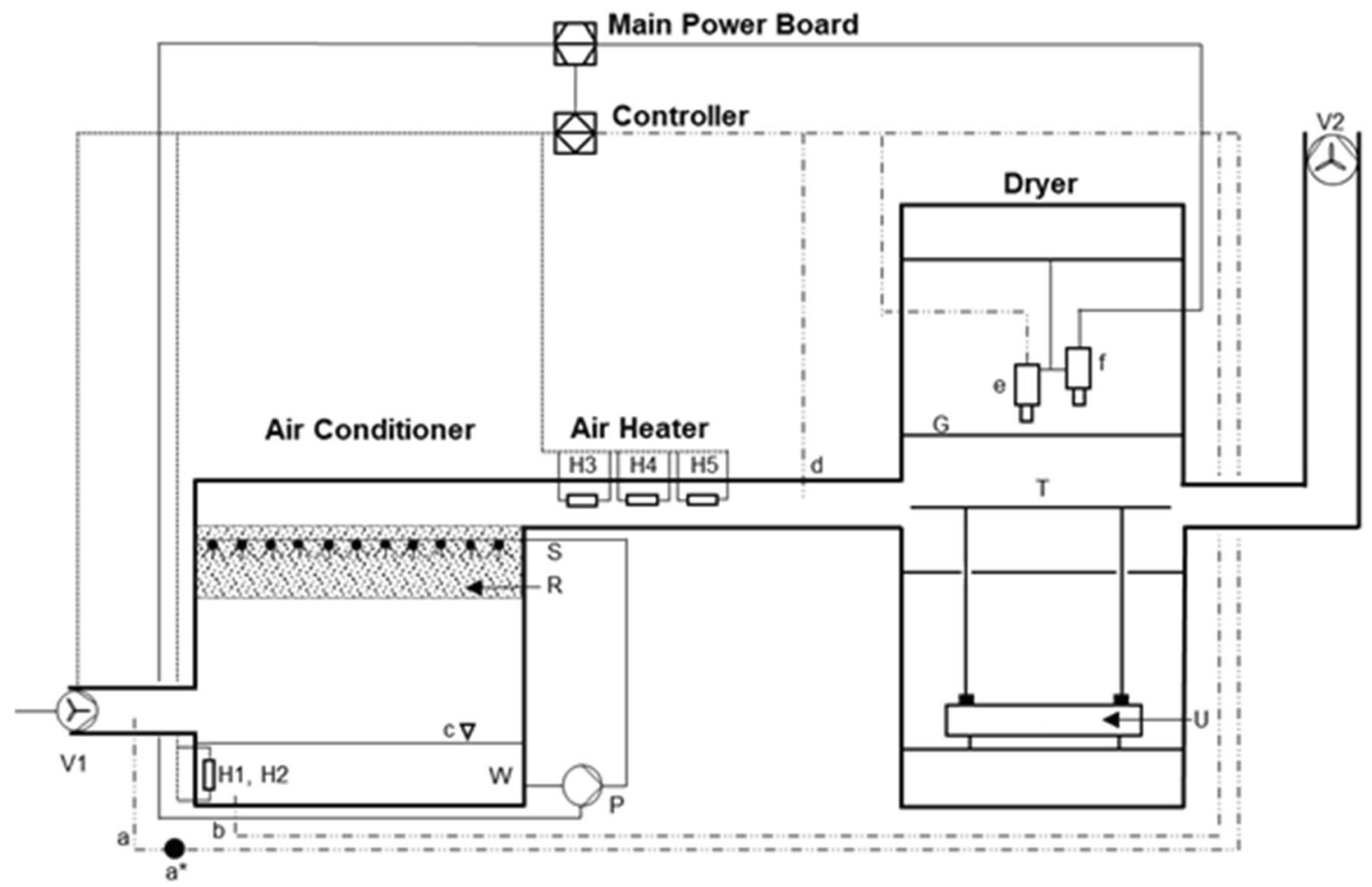

Fig. 3 Design of the developed dryer

were further processed and analysed using a methodology similar to that used by Nasirahmadi and Behroozi-Khazaei (2013) with adaptations. The image processing was performed in MATLAB R2018b (The Mathworks Inc., Natick, MA, USA), where the captured RGB images were converted to grey and further into binary images $(0,1)$ with the appropriate threshold factor. For the binary images, 0 was assigned to the background and 1 to the sample. Function bwareaopen was further applied to remove any unwanted objects within the images. The images were then masked using the masking function on RGB images in black background, which ensured that all values now belong to the image and no values are being assigned to the background. Finally, the function rgb2lab was used to convert the RGB values into LAB values for the images captured.

For calibration, a ColourChecker Classic chart (X-rite $\mathrm{GmbH}$, Planegg-Martinsried, Germany) was used to compare the values obtained using the chromameter and the RGB camera system for the 24 colour patches. The values thus acquired were further statistically analysed with GraphPad Prism 8.0 software (GraphPad Software, San Diego, CA, USA) using a transfer function as the calibration function to exclude any systematic errors (change of intercept, slope or curvature). A transfer function is an ideal function as it linearises the data sets and allows for easier comparison between the two measurement methods. A transfer function is considered ideal when a slope of 1 and intercept of 0 are obtained for the transformed Deming Regression (linear regression). The equation for the transfer function is presented in Eq. 1 .

$y=b+b_{0} x+b_{1} x^{2}$ where $b, b_{0}$ and $b_{1}$ are constant, linear coefficient and quadratic coefficient, respectively

Finally, the total colour difference was subsequently calculated using Eqs. 2-5.

$$
\begin{aligned}
& \Delta E=\sqrt{\left(\Delta L^{*}\right)^{2}+\left(\Delta a^{*}\right)^{2}+\left(\Delta b^{*}\right)^{2}} \\
& \Delta L^{*}=L_{1}^{*}-L_{0}^{*} \\
& \Delta a^{*}=a_{1}^{*}-a_{0}^{*} \\
& \Delta b^{*}=b_{1}^{*}-b_{0}^{*}
\end{aligned}
$$

where $L^{*}$ represents the lightness from black (0) to white (100), $a^{*}$ represents colours from green $(-128)$ to red $(+127)$ and $b^{*}$ colour values from blue $(-128)$ to yellow $(+127)$ (Martin (2015)). The subscript 0 denotes reference values which in this case were the values obtained from fresh carrot slices, and the subscript 1 denotes the value obtained for the corresponding drying time intervals.

\section{Product Temperature Measurement}

Product temperature was measured using the infrared system (e) depicted in Fig. 3 in combination with the PI Connect software (Optris $\mathrm{GmbH}$, Berlin, Germany) to continuously measure the temperature of the carrot samples during the drying process. A layout with 5 defined areas was designed within the software for the carrot samples to understand the temperature profile as well as 
Table 2 Information on sensors and equipment implemented within the developed dryer

\begin{tabular}{|c|c|c|c|c|}
\hline & Equipment & Model $/$ make & Accuracy & Measurement span \\
\hline $\mathrm{a}$ & $\begin{array}{l}\text { Hot wire anemometer and air } \\
\text { temperature sensor }\end{array}$ & $\begin{array}{l}\text { SVS hot wire probe, KIMO } \\
\text { Instruments, France }\end{array}$ & $\begin{array}{l} \pm 0.03 \mathrm{~m} / \mathrm{s} \\
\pm 0.25^{\circ} \mathrm{C}\end{array}$ & $\begin{array}{l}0-30 \mathrm{~m} / \mathrm{s} \\
-20 \text { to } 80{ }^{\circ} \mathrm{C}\end{array}$ \\
\hline$a^{*}$ & Transmitter & $\begin{array}{l}\text { C310, KIMO Multifunction Transmitter, } \\
\text { KIMO Instruments, France }\end{array}$ & - & - \\
\hline b & Pt-100 for water bath temperature & Class A, Pt-100 & & \\
\hline $\mathrm{c}$ & Float valve & - & - & - \\
\hline $\mathrm{d}$ & Pt-100 sensor for air temperature-inlet dryer & Class A, Pt-100 & & \\
\hline $\mathrm{e}$ & Infrared camera & PI 400, Optris GmbH, Germany & $\pm 2{ }^{\circ} \mathrm{C}$ & -20 to $900{ }^{\circ} \mathrm{C}$ \\
\hline$f$ & RGB camera & $\begin{array}{l}\text { DFK 61BUC02, The Imaging Source, USA, } \\
\text { with lens } 219 \mathrm{HB} \text {, TAMRON Co. Ltd., Japan }\end{array}$ & - & $8 \mathrm{~mm}$ focal length \\
\hline $\mathrm{e}$ & Plexiglass barrier & Gethke-Glas, Germany & - & - \\
\hline $\mathrm{H} 1-\mathrm{H} 2$ & Water bath heater $(2 \times 6 \mathrm{~kW})$; & 01090008, Helios GmbH, Germany & & \\
\hline H3-H5 & Air heaters $(3 \times 4 \mathrm{~kW})$ & 13000006, Helios GmbH, Germany & & \\
\hline $\mathrm{P}$ & Water pump & - & - & - \\
\hline $\mathrm{R}$ & Packed bed & - & - & - \\
\hline S & Spray nozzles & Custom made & - & - \\
\hline $\mathrm{T}$ & Tray & Custom made & - & - \\
\hline V1 & Inlet fan & DCMP-616-2T, Dassler GmbH, Germany & - & - \\
\hline V2 & Outlet fan & W1G250-HJ87-02, ebm-papst GmbH, Germany & - & - \\
\hline \multirow[t]{2}{*}{ W } & Water bath & Custom made & - & - \\
\hline & Controller & mTRON T, JUMO GmbH \& Co. KG, Fulda, Germany & _ & - \\
\hline
\end{tabular}

assess the temperature distribution over the tray. Figure 4 represents the designed layout for the infrared camera. Specifically, for strategy $\mathrm{P}$, the sample labelled $\mathrm{C}$ was used as control point for the input to the controller.

The software was programmed to capture the data for every $37 \mathrm{~ms}$ during the drying process. Based on the work performed by Ghoshdastidar (2018) for carrots and apples, the emissivity coefficient $\varepsilon$ was set to 0.95 .

Table 3 Process settings for experimental investigation of carrot drying

\begin{tabular}{|c|c|}
\hline Process parameters & Value \\
\hline \multicolumn{2}{|l|}{ Air } \\
\hline Temperature & $50{ }^{\circ} \mathrm{C}, 60^{\circ} \mathrm{C}, 70^{\circ} \mathrm{C}$ \\
\hline Velocity (drying chamber) & $2.2 \mathrm{~m} / \mathrm{s}$ \\
\hline Specific humidity & $8.9 \mathrm{~g}_{\mathrm{w}} / \mathrm{kg}_{\text {air }}$ \\
\hline Relative humidity (hot air-@ @ $40{ }^{\circ} \mathrm{C}$ ) & $18.7 \%$ \\
\hline Relative humidity (hot air-@ @ $50^{\circ} \mathrm{C}$ ) & $11.2 \%$ \\
\hline Relative humidity (hot air-@ @ $60^{\circ} \mathrm{C}$ ) & $6.9 \%$ \\
\hline Relative humidity (hot air-@ @ $70^{\circ} \mathrm{C}$ ) & $4.4 \%$ \\
\hline \multicolumn{2}{|l|}{ Water } \\
\hline Temperature & $20^{\circ} \mathrm{C}$ \\
\hline Flow rate & $31 / \mathrm{min}$ \\
\hline
\end{tabular}

\section{Moisture Content Analysis}

The initial moisture content within the carrot samples was determined in accordance with the AOAC International (2016) guidelines, wherein carrot samples were placed in a hot air oven at $105{ }^{\circ} \mathrm{C}$ for $24 \mathrm{~h}$ (ULM 400, Mermert $\mathrm{GmbH}+\mathrm{Co}$. KG, Schwabach, Germany). Equation 6 was used to calculate the moisture content on dry basis $\left(\mathrm{MC}_{\mathrm{db}}\right)$.

$M C_{d b}=\frac{m_{t}}{m_{d m}}-1$

where $m_{\mathrm{t}}$ is the total mass of a sample at a given time and $m_{\mathrm{dm}}$ is the absolute dry matter in a sample. The weight of the samples was recorded at set intervals for the different strategies using a precision weighing scale (Excellence E 2000 D, Sartorius AG, Göttingen, Germany, readability $0.001 \mathrm{~g}$ ). The intervals for weighing the samples of the different strategies are presented in Table 4.

After calculating the $\mathrm{MC}_{\mathrm{db}}$, the moisture ratio (MR) of the samples was calculated as it allows comparing the different samples with each other by normalising the moisture contents with their initial moisture contents and thereby displaying them as values between one and zero. MR for the carrots was calculated using Eq. 7 and Eq. 8

$M R=\frac{M C_{d b, 1}-M C_{e}}{M C_{\mathrm{d} b, 0}-M C_{e}}$ 
Fig. 4 Sample layout for product temperature measurement using the infrared camera

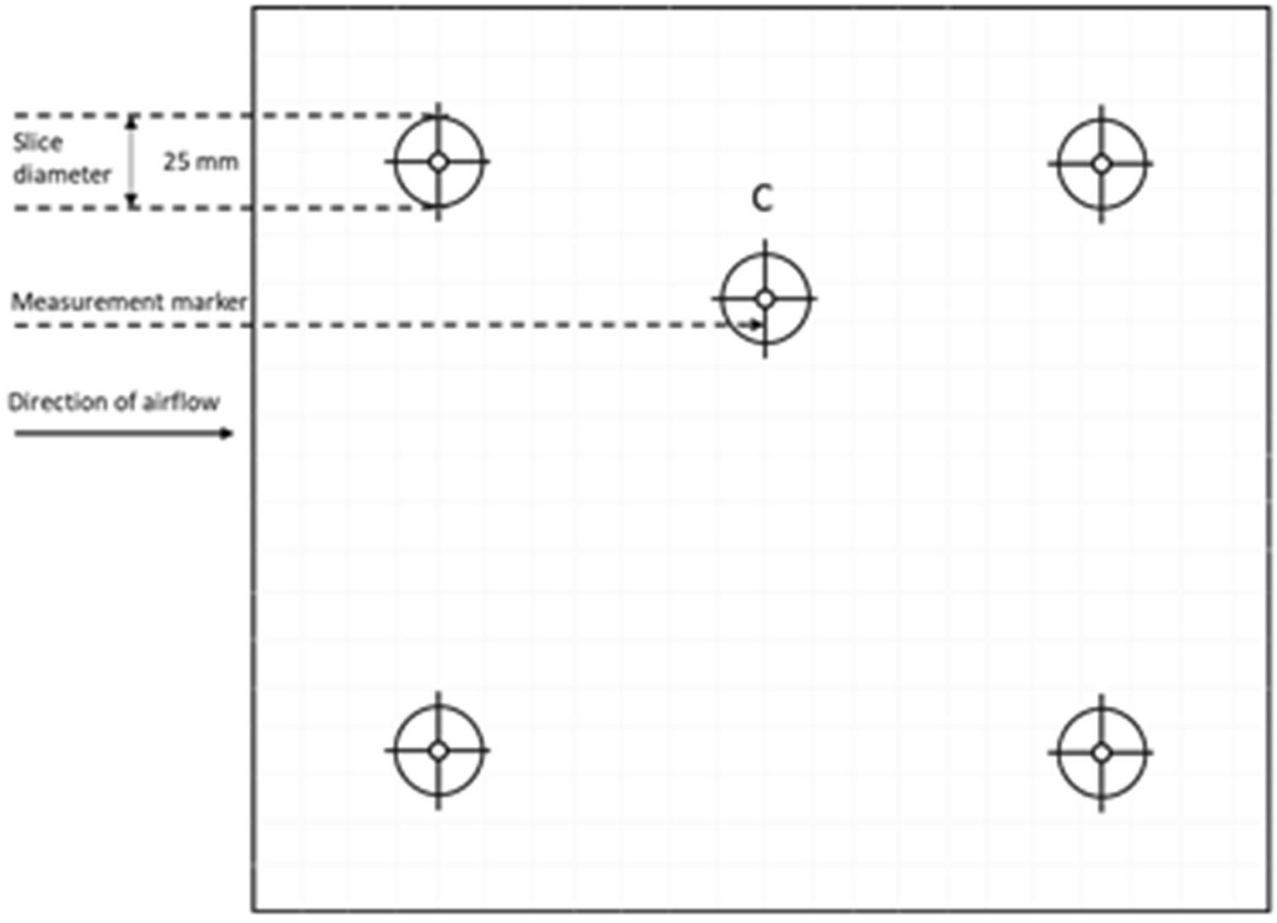

where $\mathrm{MC}_{\mathrm{db}, 1}$ is the dry basis $\mathrm{MC}$ at a given time, $\mathrm{MC}_{\mathrm{db}, 0}$ is the dry basis $\mathrm{MC}$ before drying and $\mathrm{MC}_{\mathrm{e}}$ is the equilibrium moisture content. As the influence of $\mathrm{MC}_{\mathrm{e}}$ is relatively small $(\leq 2 \%)$ (Diamante and Munro (1993), the MR equation was further simplified to Eq. 8

$M R=\frac{M C_{d b, 1}}{M C_{d b, 0}}$

The MR obtained from Eq. 8 was then used to build a model for drying behaviour for carrots. Modelling allows the prediction of drying behaviour at a given time throughout the process and thus the development of process control strategies for a product. As three different strategies were implemented within this study, it was important to evaluate the possibility of one model being fit for the different data sets. For this purpose, three of the most well-known models for thin layer drying of food products particularly Newton, Page and the Henderson \& Pabis model (Agrawal \& Singh, 1977;

Table 4 Sampling intervals for moisture content of the different strategies for all three temperatures

\begin{tabular}{|c|c|c|c|c|}
\hline \multirow[t]{3}{*}{ Interval } & \multicolumn{4}{|l|}{ Strategy } \\
\hline & A & $\mathrm{P}$ & $\mathrm{S} 40$ & $\mathrm{~S} 50$ \\
\hline & \multicolumn{4}{|c|}{ Time section in minutes } \\
\hline $10 \mathrm{~min}$ & & $0-60$ & & \\
\hline $20 \mathrm{~min}$ & $0-60$ & & $0-120$ & $0-120$ \\
\hline $30 \mathrm{~min}$ & $60-180$ & $60-150$ & $120-180$ & $120-180$ \\
\hline
\end{tabular}

Ayensu, 1997; Henderson \& Pabis, 1961) were used to fit the drying curves. They are represented by Eqs. 9, 10 and 11 .

$M R=\exp (-K t)$

$M R=\exp \left(-K t^{n}\right)$

$M R=1+a t+b t^{2}$

where $a, b$ and $K$ are the drying constants, $t$ is the drying time in minutes and $n$ is the drying exponent.

Non-regression analysis similar to that performed by Sturm et al. (2020) was conducted within this study. The analysis was performed using GraphPad Prism 8.0 software (GraphPad Software, San Diego, CA, USA ). Adjusted $R^{2}$ $\left(R^{2}\right.$ adj $)$, root mean square error (RMSE) and Akaike information criterion (AICc) were used to evaluate the appropriateness of the models. $R_{\text {adj }}^{2}$ values rather than $R^{2}$ values were used as these values have been adjusted to the number of predictors in the model. AICc is a model selection criterion that allows for estimation of the most likely model for the selected data. In general, these values are not negative (Sturm et al., 2020). However, regression analysis can potentially lead to negative values (Burnham, 2002) and the lower the AICc values, the better the conformity of the model to the data. A model is estimated fit for a data if the values for $R^{2}$ adj are high and RMSE and AICc are low.

\section{Total Carotenoid Retention}

The measurement for total carotenoids (TC) was carried out in the same manner as reported by Md Saleh et al. (2019) 
wherein $100 \mathrm{mg}$ of carrot tissue from the sample extracted at specific moisture contents and time interval was mixed with a solution of hexane, acetone and ethanol in a ratio of $2: 1: 1$ to extract the carotenoids from the tissues. The mixture was further placed in a laboratory homogeniser (T 25, IKA-Werke $\mathrm{GmbH} \& \mathrm{CO}$. KG, Staufen, Germany) for $2 \mathrm{~min}$ at $8000 \mathrm{rpm}$ and later on stored at $4{ }^{\circ} \mathrm{C}$ for $1 \mathrm{~h}$ in order to dissolve the carotenoids in the solution. For phase separation, $5 \mathrm{ml}$ of distilled water was added to the solution. The non-aqueous phase was then separated and analysed by use of an UV/Vis spectrophotometer (GENESYS 10 Series, Thermo Electron Corporation, USA). Equation 12 was used for determination of total carotenoids of the carrot samples.

$T C=\frac{A \times V_{1}}{A_{1 \%}} \times C^{1 \%}$

where $A$ is the absorbance of the sample, $V_{1}$ the dilution factor, $A_{1 \%}$ the extinction coefficient of the $1 \%$ solution and $C^{1 \%}$ the carrot tissue concentration of the $1 \%$ solution (10 $\mathrm{mg} / \mathrm{ml})$.

\section{Water Activity}

For water activity measurement, a portable water activity meter (LabSwift-aw, Novasina AG, Lachen, Switzerland) was used. To ensure constant environmental conditions for the measurement, the water activity meter was placed in a climatic chamber with a constant temperature of $25^{\circ} \mathrm{C}$ (VöTSCH VCL 4010, Vötsch Industrietechnik GmbH, Balingen, Germany). Samples were extracted hourly from the dryer until the end of the drying period to understand and observe the development in dependence of strategy and settings.

\section{Rehydration Ratio}

Rehydration is considered as a measure for the injuries caused to the product due to processes such as drying (Lewicki, 1998). It consists of three processes wherein the first stage involves imbibition of the water in the dried product, followed by swelling and finally leaching of solubles (Krokida \& Marinos-Kouris, 2003; Lewicki, 1998). Thus, it is important to calculate the rehydration ratio (RR) as it allows understanding the capability of the dried material to restore to its original state.

$\mathrm{RR}$ is the ratio between the weight of the rehydrated sample to its initial weight (Lewicki, 1998). In this investigation, dried carrot samples were weighed on a precision weighing scale (Excellence E 2000 D, Sartorius AG, Göttingen, Germany, readability $0.001 \mathrm{~g}$ ) to determine the final weight. The samples were then immersed in a beaker filled with $150 \mathrm{ml}$ of distilled water which was heated to $95^{\circ} \mathrm{C}$. The samples were submerged for $10 \mathrm{~min}$ while stirring every $30 \mathrm{~s}$ to break away air bubbles adhering to the samples. Subsequently, the samples were drained on a metal sieve at room temperature for $5 \mathrm{~min}$, before blotting them with a filter paper for 2 min and finally weighing them. The rehydration ratio was thus calculated using Eq. 13.

$R R=\frac{m_{r}}{m_{0}}$

where $m_{\mathrm{r}}$ is the weight of the rehydrated sample and $m_{0}$ is the weight of the sample before drying.

\section{Data Aggregation}

Within the conducted experimental investigation, a large amount of data was collected which revealed the necessity for a sophisticated data aggregation and processing methodology that would allow for data structuring, organising and storing as well as ensure prevention of random human errors. Therefore, a highly efficient algorithm was developed which first imported experimental data from different files and data formats, then processed and calculated necessary information such as $\mathrm{MC}_{\mathrm{wb}}, \mathrm{MC}_{\mathrm{db}}, \mathrm{MR}$ (using Eqs. 6-8), $\Delta E$ (using Eqs. $2-5$ ) and RR (using Eq. 13) values for each carrot slice within each experiment. This was then further averaged both carrotand experiment-wise for each strategy and finally organised to export the data appropriately for visualisation. This resulted in a data set of more than 100,000 entries. Table 5 provides an overview of the values calculated from the imported data.

The developed algorithm was built using the open-source programming language Python, using libraries of pandas for generating and importing Excel files (McKinney, 2010) and NumPy for associated calculations (van der Walt et al., 2011) as well as IPython (Perez \& Granger, 2007) and jupyter (Kluyver et al., 2016) open-source extensions for development of code.

\section{Energy Calculation}

Calculation of the mass specific energy demand of the product was conducted using Eqs. 14-19 (Aghbashlo et al., 2008; Motevali et al., 2011; Ndisya et al., 2020):

$$
\begin{aligned}
& \frac{Q_{m}=\int_{0}^{t_{e n d}} \dot{Q}_{t} d t}{\sum m_{\text {carrot }, i}} \\
& \frac{Q_{m, j}=\dot{Q}_{t, j} \times \Delta t_{j}}{\sum m_{\text {carrot }, i}} \\
& \dot{Q}_{t}=\dot{m}_{a} \times c_{p, a} \times \Delta T_{a} \\
& \dot{m}_{a}=\dot{V}_{a} \times \rho_{a} \\
& \dot{V}_{a}=A \times v_{a} \\
& \Delta T_{a}=\left(\vartheta_{a}-\vartheta_{\infty}\right)
\end{aligned}
$$


Table 5 Values and averages calculated using developed algorithms

\begin{tabular}{llll}
\hline Value & Per sample & Average per carrot & Average per experiment \\
\hline $\mathrm{MC}_{\mathrm{wb}}$ & $\mathrm{X}$ & $\mathrm{X}$ & $\mathrm{X}$ \\
$\mathrm{MC}_{\mathrm{db}}$ & $\mathrm{X}$ & $\mathrm{X}$ & $\mathrm{X}$ \\
$\mathrm{MR}$ & $\mathrm{X}$ & $\mathrm{X}$ & $\mathrm{X}$ \\
$\mathrm{RR}$ & $\mathrm{X}$ & $\mathrm{X}$ & $\mathrm{X}$ \\
$L^{*}$ & & $\mathrm{X}$ & $\mathrm{X}$ \\
$a^{*}$ & & $\mathrm{X}$ & $\mathrm{X}$ \\
$b^{*}$ & & $\mathrm{X}$ & $\mathrm{X}$ \\
$\Delta E$ & & $\mathrm{X}$ & $\mathrm{X}$ \\
$L^{*}{ }_{\mathrm{RGB}}$ & $\mathrm{X}$ & $\mathrm{X}$ \\
$a^{*}{ }_{\mathrm{RGB}}$ & $\mathrm{X}$ & $\mathrm{X}$ \\
$b^{*}{ }_{\mathrm{RGB}}$ & & $\mathrm{X}$ & $\mathrm{X}$ \\
$\Delta E_{\mathrm{RGB}}$ & $\mathrm{X}$ & $\mathrm{X}$ \\
Total carotenoids & & $\mathrm{X}$ & $\mathrm{X}$ \\
$\mathrm{TC}$ retention & & $\mathrm{X}$ & $\mathrm{X}$ \\
\hline
\end{tabular}

where $\dot{Q}_{t}$ is the rate of heat flow in a given time interval in $\mathrm{W}, \Delta t$ is the time interval in $\mathrm{s}, m_{\mathrm{carrot}, i}$ is the mass of a sample in $\mathrm{kg}$ (equivalent to $\mathrm{MC}_{\mathrm{wb}}$ ), $\dot{m}_{\mathrm{a}}$ is the mass flow of air in $\mathrm{kg} / \mathrm{s}$, $c_{\text {p,a }}$ is the specific isobaric heat capacity of air in $\mathrm{J} /(\mathrm{kg} \cdot \mathrm{K}), \dot{V}_{\mathrm{a}}$ is the volumetric flow rate of air in $\mathrm{m}^{3} / \mathrm{s}, \rho_{\mathrm{a}}$ is the density of air in $\mathrm{kg} / \mathrm{m}^{3}, A$ is the cross-sectional area of the air flow channel in $\mathrm{m}^{2}$ and $v_{\mathrm{a}}$ is the velocity of air in $\mathrm{m} / \mathrm{s}$.

Within the calculations, the following assumptions were made:

- Density of air was assumed to be constant, since variation within the temperature ranged less than $2 \%$.

- The outside temperature was also presumed to be constant, as variations were only within $\pm 1{ }^{\circ} \mathrm{C}$.

- Since the constructive conditions of the dryer (see Table 3) assure a constant mass flow of air, the velocity of the air was measured at one temperature and mass flow was calculated using the density of air at that temperature according to Eq. 15 and then seen as a constant value.

For strategy A and strategies S50/S40, Eq. 15 was used to calculate the energy demand as the air temperature was constant throughout the drying process. For strategy S50/S40, the demand before and after the inflection point was calculated separately and then summed up. For strategy P, Eq. 14 was used to calculate the specific energy demand as the process was started at room temperature and air temperature changed continuously until the product reached the desired set temperature. To achieve precise results, the temperature data measured from the sensors (a, $d$ and $f$ ) in Fig. 3 at a time interval of $5 \mathrm{~s}$ was used for calculations which led to several thousand individual data points that need to be calculated. For this purpose, an algorithm similar to the one in "Data aggregation" was developed, so as to automatically process the input data and calculate and export the results.

\section{Results and Discussion}

The results obtained for the investigations performed within this study are further discussed in detail within this section. A representative image of the changes in the carrot samples during the drying process obtained from drying fresh carrots is shown in Fig. 5.

\section{Drying Behaviour}

Figures 6, 7 and 8 depict the drying behaviour of the samples dried using the three different strategies under the respective drying temperatures. For strategy A (Fig. 6), the results obtained from the product temperature development show clear phase transitions of the product during the drying phase. The transition from the first phase to the second phase is observed at an MR of roughly 0.4 while that from the second phase to the third phase is observed at an MR of about 0.2 (Sturm et al., 2014) (Sturm, 2018). As for time required for the product temperature to reach the set air temperature, this was largely dependent on the drying temperature in focus. The lower the air temperature, the longer the amount of drying time required and vice versa. These results are analogous to those observed by von Gersdorff et al. (2017) for beef and by Shrestha et al. (2020) for apples. Thus, this indicates that air temperature plays a significant role in the drying process. In addition to these results, minor fluctuations are seen for all three temperatures especially after the product temperature has reached the set air temperature. During pre-tests for the experimental investigation, a considerable time lag between the measured value from the sensor and the corresponding controller reaction was observed. To compensate this lag, an offset was set on the sensor so as to allow the controller to maintain a 
Fig. 5 Changes in carrot sample during drying process (strategy A, $70{ }^{\circ} \mathrm{C}$ )
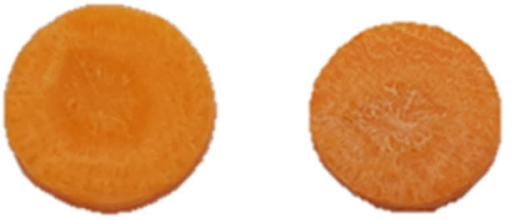
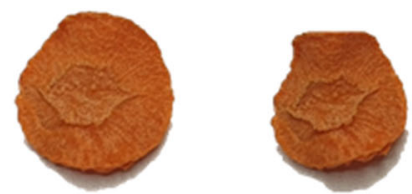

constant set temperature with a short reaction time. This, in combination with the self-optimisation function within the controller, resulted in the corresponding fluctuations. The controller implemented within the present study consists of a selfoptimisation function that allows maintaining the set temperatures.

For samples dried with strategy $\mathrm{P}$, as observed in Fig. 7, the phase transitions are slightly different to those in strategy A. In this strategy, the first phase of the product is a warmup phase as both the air and product temperatures are rising. This warmup phase is due to the cold start wherein the drier is not pre-heated to the set temperature but rather started as soon as the samples are placed within the drying chamber. The effect of cold start can also be observed on the product temperature curve at $0 \mathrm{~min}$, wherein a small dip is observed at the beginning of the drying process. This dip is due to the introduction of samples that were colder than the temperature of the tray for area measured by the infrared camera. Like strategy A, the transition from the second to the third phase begins at $0.2 \mathrm{MR}$. As for the transition of the air temperature, the air temperature keeps increasing until the product temperature has reached the set point. However, as the air temperature was limited to a maximum of $100{ }^{\circ} \mathrm{C}$, this temperature remained constant until the product reached the set temperature if otherwise air temperature had risen higher. Due to this limitation, a distinguished trend of the product temperature is also observed. As soon as the set product temperature was achieved, the air temperature started decreasing to maintain a constant product temperature throughout the drying process.
According to the investigation performed by Sturm et al. (2014), the reduction in air temperature is quite crucial to maintain the product temperature as the difference between the wet bulb and dry bulb temperature decreases. In terms of time, the overall drying time was about $66 \%$ shorter with this strategy for all three temperatures as compared to the other two strategies. In the case of all three temperatures, the product and air temperature reached equilibrium around $60 \mathrm{~min}$, but the drying process was continued to reach the targeted MR of 0.023 .

Figure 8 shows the drying behaviour of samples for strategy S50 and S40. This strategy shows a similar drying behaviour to strategy A other than the expected stepwise decrease in air temperature by $10^{\circ} \mathrm{C}$ for $\mathrm{S} 50$ and by $20^{\circ} \mathrm{C}$ for $\mathrm{S} 40$ at the inflection point. The decreased temperature was then maintained constant until the end of the drying period. The overall time required to achieve the target MR was the longest for this strategy with S50 requiring $150 \mathrm{~min}$ while S40 required $180 \mathrm{~min}$ as compared to strategy A.

\section{Modelling Curve}

Studies conducted by Doymaz (2004), Sacilik and Elicin (2006), Akoy (2014) and Doymaz and Özdemir (2014) have investigated different drying models for various products. However, in the case of most of these studies, only one drying strategy was implemented for model investigation. Within this study, three models were investigated to determine a single model that agrees with all three strategies (A, P, S50/S40). For all three strategies, $R_{\text {adj }}^{2}$ RMSE, AICc, and the percentage of
Fig. 6 Drying behaviour of carrot samples under strategy A-air temperature-controlled strategy for $50{ }^{\circ} \mathrm{C}, 60^{\circ} \mathrm{C}$ and $70{ }^{\circ} \mathrm{C}$

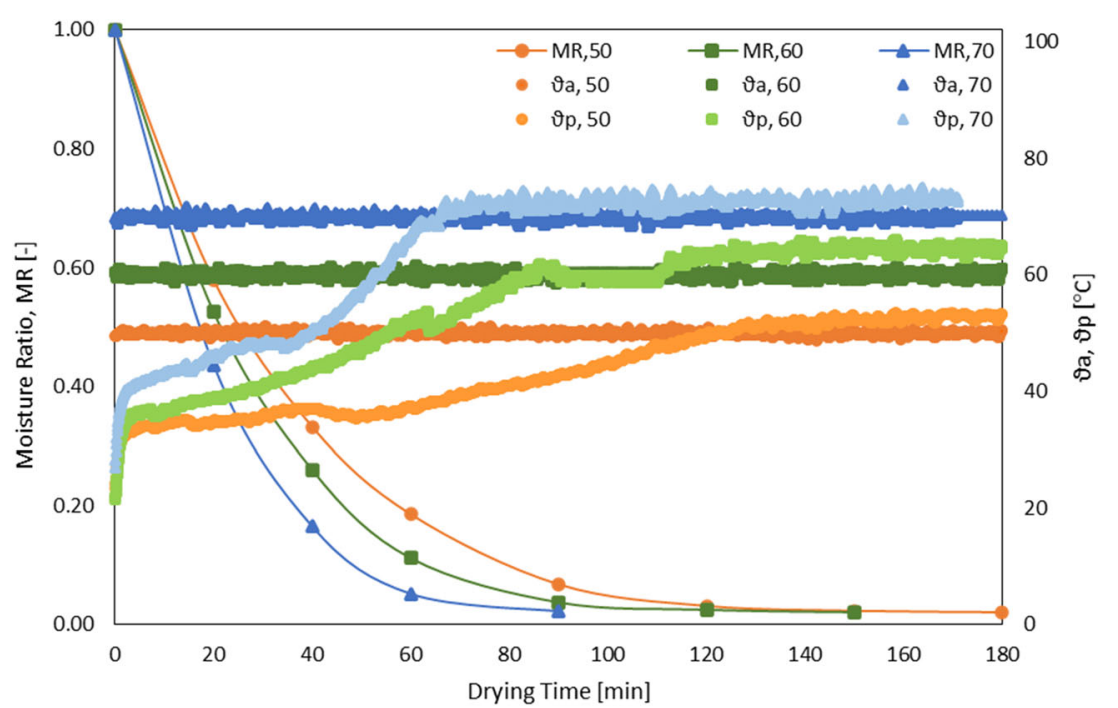


Fig. 7 Drying behaviour of carrot samples under strategy $\mathrm{P}$ product temperature-controlled strategy for $50{ }^{\circ} \mathrm{C}, 60{ }^{\circ} \mathrm{C}$ and 70 ${ }^{\circ} \mathrm{C}$

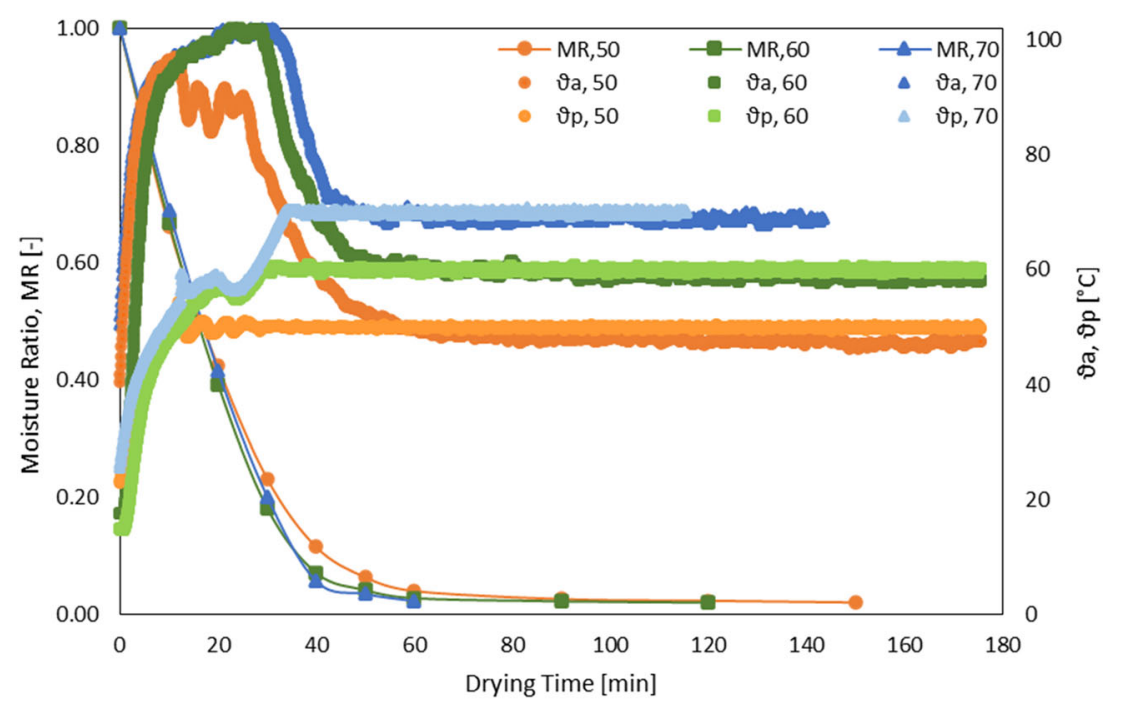

likelihood were used to estimate the goodness of fit. As observed in Table 7, high $R_{\text {adj }}^{2}$ and lower RMSE values were obtained for the Page model.

Comparing the Newton model to the Page model, it was observed that the Newton model showed better conformity only to strategy A. A similar comparison was also performed between the Henderson and Pabis and Page models. The results obtained from the comparison concluded that the Henderson and Pabis model was a partial fit for strategy A and strategy S50/S40. However, it had significant shortcomings to the fit for strategy P. The Page model, on the other hand, shows better conformity to all of the implemented strategies confirming the findings of Doymaz (2004). Therefore, it was chosen as the model for this study. Table 6 presents the results obtained from the comparison performed between the Page model and the Henderson and Pabis model while Table 7 presents the final, $R_{\text {adj }}^{2}$, RMSE and AICc values for the Page model. The resulting curves together with the experimental data sets and standard deviation are depicted in Fig. 9.

\section{Development of Colour}

Colour is one of the essential quality criteria that influence the purchasing decision of the consumers (Ratti, 2009). Processes such as drying can cause susceptible degradation in the naturally occurring pigments (Awuah et al., 2007) and in turn lead to changes in colour. Additionally, the changes in colour can also potentially help understand the transitions within the product during the drying process, and thus ease the implementation of non-invasive measurement techniques.

\section{Calibration and Method Validation}

Figure 10 provides the results of the statistical analysis for $L^{*}$, $a^{*}$ and $b^{*}$ values obtained from the colour checker chart from both the systems. The black lines in Fig. 10a-c present linear regression (Deming regression) while the red line represents non-linear regression (second-order polynomial).
Fig. 8 Drying behaviour of carrot samples under strategy S50/ S40 - stepwise temperaturecontrolled strategy for $50{ }^{\circ} \mathrm{C}, 60$ ${ }^{\circ} \mathrm{C}$ and $70{ }^{\circ} \mathrm{C}$

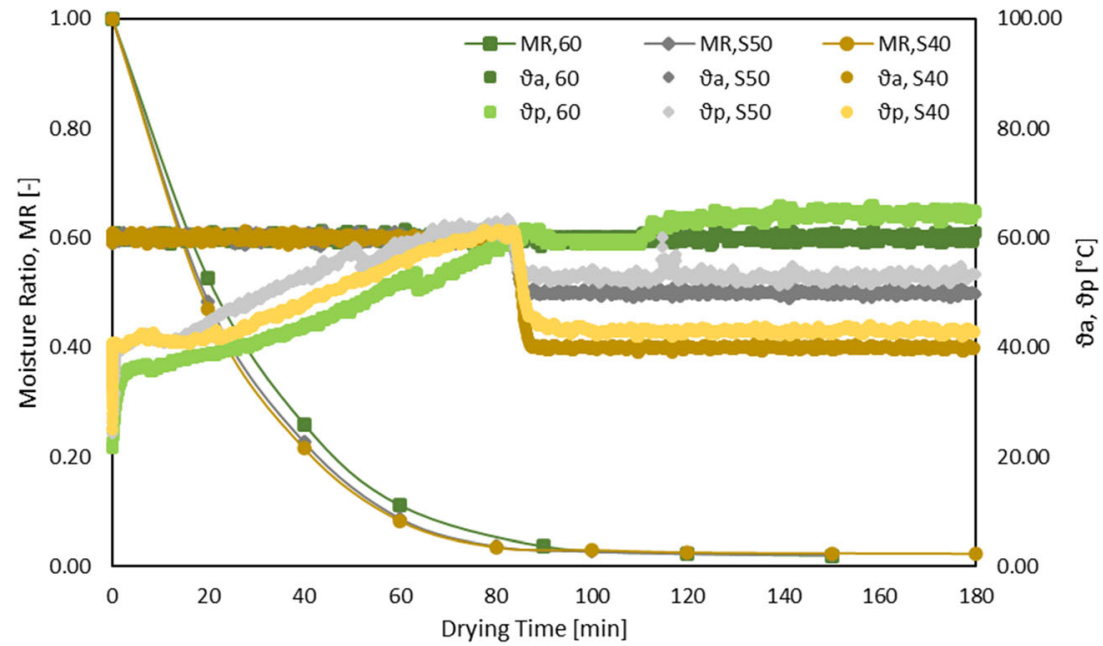


Table 6 Results of the comparison between the Page model and the Henderson and Pabis model where $B^{*}$ is the probability it is correct (\%), $C^{*}$ is ratio of probabilities and $D^{*}$ is the difference in $\mathrm{AICc}$

\begin{tabular}{|c|c|c|c|c|c|c|c|c|c|}
\hline \multirow[t]{2}{*}{ Strategy } & \multicolumn{3}{|l|}{ A } & \multicolumn{3}{|l|}{$\mathrm{P}$} & \multicolumn{3}{|l|}{$\mathrm{S}$} \\
\hline & $B^{*}$ & $C^{*}$ & $D^{*}$ & $B^{*}$ & $C^{*}$ & $D^{*}$ & $B^{*}$ & $C^{*}$ & $D^{*}$ \\
\hline $50^{\circ} \mathrm{C}$ & 69.77 & 2.31 & -1.67 & 99.41 & 168.70 & -10.26 & & & \\
\hline $60^{\circ} \mathrm{C}$ & 82.81 & 4.82 & -3.14 & 99.99 & 6927 & -17.69 & & & \\
\hline $70{ }^{\circ} \mathrm{C}$ & 94.59 & 17.47 & -5.72 & 99.98 & 6383 & -17.52 & & & \\
\hline $60^{\circ} \mathrm{C} \Delta 10$ & & & & & & & 65.99 & 1.94 & -1.33 \\
\hline $60^{\circ} \mathrm{C} \Delta 20$ & & & & & & & 53.85 & 1.17 & -0.31 \\
\hline
\end{tabular}

Based on the results obtained, it is observed that nonliner regression is a better fit as compared to linear regression especially in the case of $L^{*}$ wherein a curvature is observed. For $a^{*}$ and $b^{*}$, the difference between linear and non-linear regression is insignificant; however, application of both regressions allowed for data analysis flexibility. For calibration purposes, the transfer function was applied to the above data set so as to exclude the observed systematic error (curvature in the case of $L^{*}$ ) and obtain transformed data set values for a better comparison between the chromameter and the RGB camera system.

Table 8 presents the equations and the $R_{\text {adj }}^{2}$ for $L^{*} a^{*} b^{*}$ after applying the transfer function on the calibration data sets (i.e. colour checker chart).

The calibration equations mentioned within Table 8 were further implemented to the experimental data values obtained from the camera to compensate for the shortcomings of the non-invasive methodology. In addition to regression analysis, the Bland-Altman plot (Fig 11) was also plotted in order to check the agreement of the transformed data sets. The graph represents the average of the two methods on the $x$-axis while the difference between the two methodologies is displayed on the $y$-axis for $L^{*}, a^{*}$ and $b^{*}$, respectively.

The Bland-Altman plot for the transformed data set shows no curvature, as well as no trend for both $x$ - and $y$-axes. Furthermore, no pattern between the data points is observed after applying the transfer function which in turn indicates a good agreement between the chromameter and the camera system.

\section{Effect of Drying Strategies on Colour}

Figure 12 depicts the $\Delta E$ as a function of the moisture ratio for the camera system under strategy A, P and S50/S40, respectively. The $\Delta E$ values were calculated using the transformed experimental $L^{*} a^{*} b^{*}$ values using the equations mentioned in Table 8.

From the analysis performed, it is observed that all three strategies have considerable effect on the $\Delta E$ values of the sample. For strategy A, the maximum colour degradation is observed for $70^{\circ} \mathrm{C}$ with $\Delta E$ of 16.1 . For $50^{\circ} \mathrm{C}$ and $60^{\circ} \mathrm{C}, \Delta E$ values of 15.8 and 14.9 were obtained, respectively. Studies performed by Saxena et al. (2012) on jackfruit bulbs and by Doymaz (2017) and Md Saleh et al. (2019) on carrots have reported the influence of drying temperature and drying time on total colour changes. According to Saxena et al. (2012) with increase in drying time and drying temperature, the authors observed a decrease in yellowness and an increase in browning of jackfruit bulbs. An investigation performed by Md Saleh et al. (2019) showed that carrot slices of $3 \mathrm{~mm}$ thickness have maximum degradation at $50{ }^{\circ} \mathrm{C}$ and $70{ }^{\circ} \mathrm{C}$, which are concurrent to the findings from the current study. Degradation of colour in the carrot slices can be associated to the oxidation of carotenoids which leads to the formation of colourless lower molecular products such as beta ionone that eventually leads to the degradation of pigments within the carrot slices (Sturm \& Hensel, 2017).

Within strategy $\mathrm{P}$, the highest colour degradation was observed for $70{ }^{\circ} \mathrm{C}$, followed by $60{ }^{\circ} \mathrm{C}$ and $50{ }^{\circ} \mathrm{C}$ with
Table $7 R_{\text {adj }}^{2}$, RMSE and AICc values for the Page model for different drying strategies

\begin{tabular}{|c|c|c|c|c|c|c|c|c|c|}
\hline \multirow[t]{2}{*}{ Strategy } & \multicolumn{3}{|l|}{ A } & \multicolumn{3}{|l|}{$\mathrm{P}$} & \multicolumn{3}{|l|}{$\mathrm{S}$} \\
\hline & $R_{\text {adj }}^{2}$ & RMSE & $\mathrm{AICc}$ & $R_{\text {adj }}^{2}$ & RMSE & AICc & $R_{\text {adj }}^{2}$ & RMSE & $\mathrm{AICc}$ \\
\hline $50{ }^{\circ} \mathrm{C}$ & 0.999 & 0.017 & -66.76 & 0.998 & 0.016 & -83.16 & & & \\
\hline $60{ }^{\circ} \mathrm{C}$ & 0.999 & 0.011 & -60.77 & 0.998 & 0.015 & -75.09 & & & \\
\hline $70^{\circ} \mathrm{C}$ & 0.999 & 0.010 & -39.56 & 0.998 & 0.017 & -54.67 & & & \\
\hline $60^{\circ} \mathrm{C} \Delta 10$ & & & & & & & 0.998 & 0.013 & -69.00 \\
\hline $60^{\circ} \mathrm{C} \Delta 20$ & & & & & & & 0.998 & 0.015 & -66.52 \\
\hline
\end{tabular}




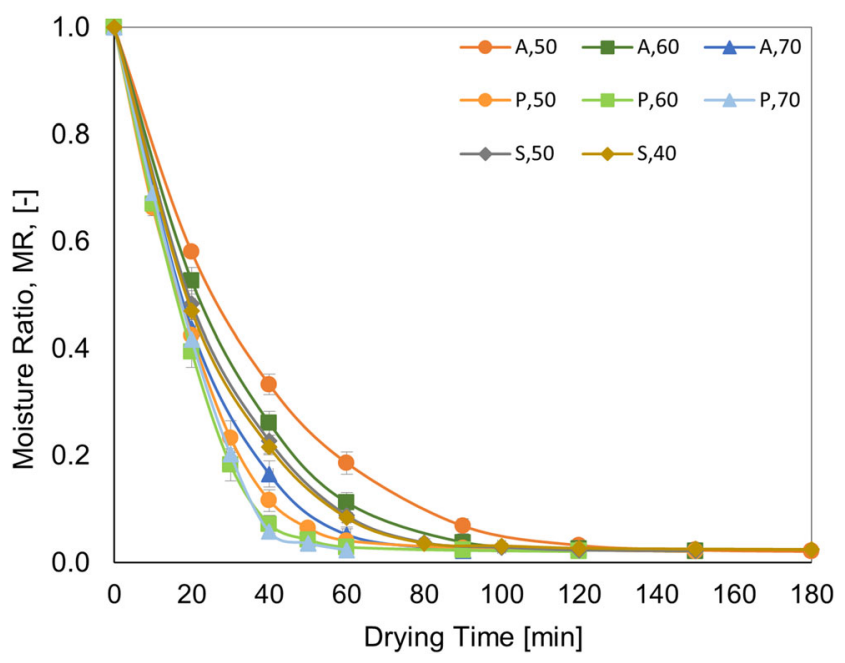

Fig. 9 Modelled drying curves for different drying strategies

corresponding $\Delta E$ values of $27.48,23.80$ and 17.34 . However, the highest increase is observed only in the initial phase of drying. As the sample reached a moisture ratio of 0.2 , a constant value for colour change is observed until the end of the drying process. Degradation of colour is associated to the enzymatic and non-enzymatic reactions occurring on the product surface. Furthermore, as pigments are sensitive to heat, high temperatures during the drying process lead to the destruction of pigments and hence the associated significant change in colour. In the case of strategy $\mathrm{P}$, air temperature up to $100{ }^{\circ} \mathrm{C}$ is achieved at the initial phase of drying and therefore significant colour changes are observed during this period. Chen and Martynenko (2013) also conducted realtime investigation of colour changes using a CCD camera for high bush and wild blueberries. They observed that temperature plays an important role for colour change especially in the first 30 min of drying and temperatures above $55^{\circ} \mathrm{C}$ significantly contribute to the total colour degradation. For strategy $\mathrm{P}$, the high temperatures at the beginning combined with product set point temperatures of $60^{\circ} \mathrm{C}$ and $70^{\circ} \mathrm{C}$ led to significant degradation of colour in the carrot samples whereas samples dried at $50^{\circ} \mathrm{C}$ are closer to values obtained through strategy A, thus agreeing with the results obtained by Chen and Martynenko (2013).

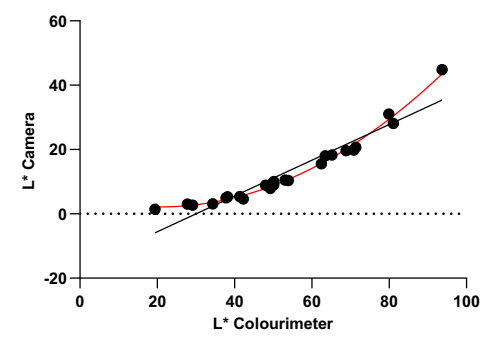

(a)

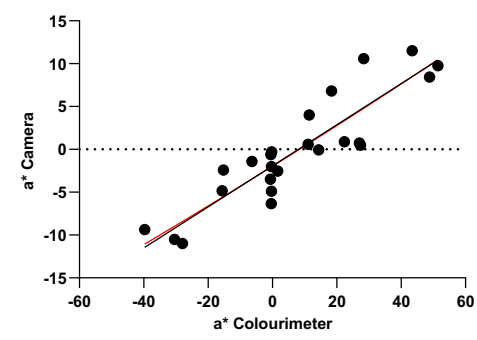

(b)
Table 8 Transfer function equations and $R_{\text {adj }}^{2}$ for $L^{*} a^{*} b^{*}$

\begin{tabular}{lll}
\hline Parameters & Equation & $R_{\text {adj }}^{2}$ \\
\hline$L^{*}$ & $y=-23.63+2.997 x-0.033 x^{2}$ & 0.969 \\
$a^{*}$ & $y=-09.46+3.456 x-0.042 x^{2}$ & 0.796 \\
$b^{*}$ & $y=-15.22+3.737 x-0.013 x^{2}$ & 0.780 \\
\hline
\end{tabular}

Comparing the results of S50/S40 to those of strategy A $\left(60{ }^{\circ} \mathrm{C}\right)$, it is observed that $\mathrm{S} 50$ behaves rather similarly to strategy A as compared to S40. Final $\Delta E$ values of 14.4 and 10.0 were observed for S50 and S40, respectively. In the case of $\mathrm{S} 40$, an increase in $\Delta E$ values is observed until the inflection point, after which the $\Delta E$ values are seen to decrease. It is believed that shrinkage of the $\mathrm{S} 40$ samples played a vital role in the total colour change. A study conducted by Wang and Brennen, 1995 revealed that potato tissue dried at lower temperature had higher shrinkage than that at higher temperature. At lower drying temperatures, the moisture within the sample is transported in a flat manner, thus causing minimum stress with the sample, and hence allowing for uniform shrinkage of the sample. At higher drying temperatures, the samples dry quickly which causes the surface to harden and hence are prevented from shrinking significantly (Mahiuddin et al., 2018). Additionally, depending on the structural properties such as density, shape and size of the sample, the interaction and scattering of light could vary at different degrees. And hence deformations such as shrinkage can cause further problems for optical measurement systems like RGB cameras for colour measurement. The effect of shrinkage on RGB camera measurements can be observed in Fig. 13 wherein high standard deviation values are obtained for almost all the samples after reaching an MR of 0.2 .

Overall, the results obtained from the stepwise strategy are in agreement with the investigations performed by Chua et al. (2000) and Chua et al. (2001b) on bananas and guavas which shows that stepwise drying leads to minimum overall changes in colour as compared to continuous drying. This could be due to the presence of surface moisture that forms a protective layer during the initial drying phase (Sturm et al., 2009). Furthermore, in a recent investigation performed by $\mathrm{Md}$

Fig. 10 Linear and non-linear regression analyses performed on 24 colour patches of the colour checker chart for the three colour parameters $\mathbf{a} L^{*}, \mathbf{b} a^{*}$ and $\mathbf{c} b^{*}$ 


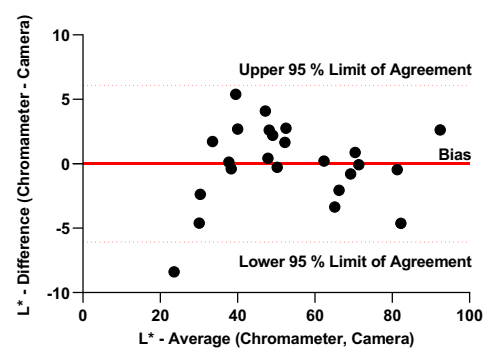

(a)

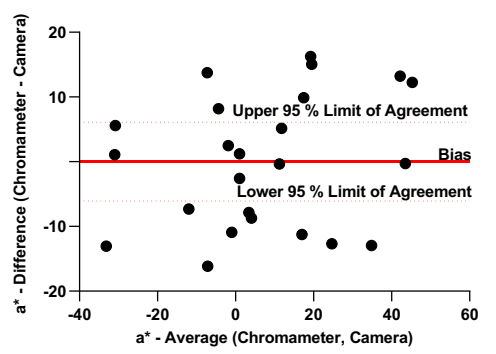

(b)

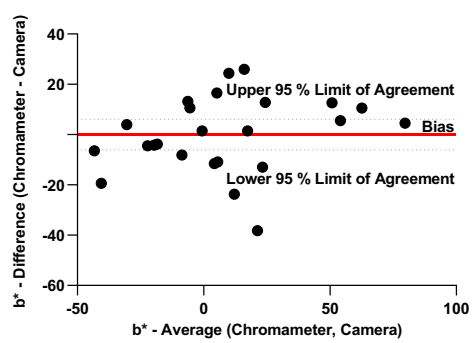

(c)

Fig. 11 Bland-Altman plot for transformed colour checker data set for the three colour parameters $\mathbf{a} L^{*}, \mathbf{b} a^{*}$ and $\mathbf{c} b^{*}$

Saleh et al. (2020) on intermittent drying of carrots with a tempering period of $3 \mathrm{~h}$ at $60^{\circ} \mathrm{C}$, the authors also observed minimal colour change with $\Delta E$ of 8.1. As no tempering of samples was conducted within the current study, a higher colour change was observed in comparison to Md Saleh et al. (2020). Furthermore, the difference between the values obtained in the studies could be due to the varying measurement technique with Md Saleh et al. (2020) using only a chromameter while the current study uses an RGB camera system calibrated against the chromameter.

\section{Total Carotenoid Retention}

\section{Effect of Drying Strategy on Total Carotenoid Retention}

Many fruits and vegetables such as carrots and sweet potatoes consist of high concentrations of $\beta$-carotene. With $\beta$-carotene being such an important factor of carotenoids, their degradation also significantly affects the overall TCR content. $\beta$ Carotene is a hydrocarbon that belongs to carotenes which is one of the two classes of the carotenoid molecules. It has a highly unsaturated structure, which makes it prone to degradation especially to isomerisation and oxidation at high temperature (Pénicaud et al., 2011). During the drying process,

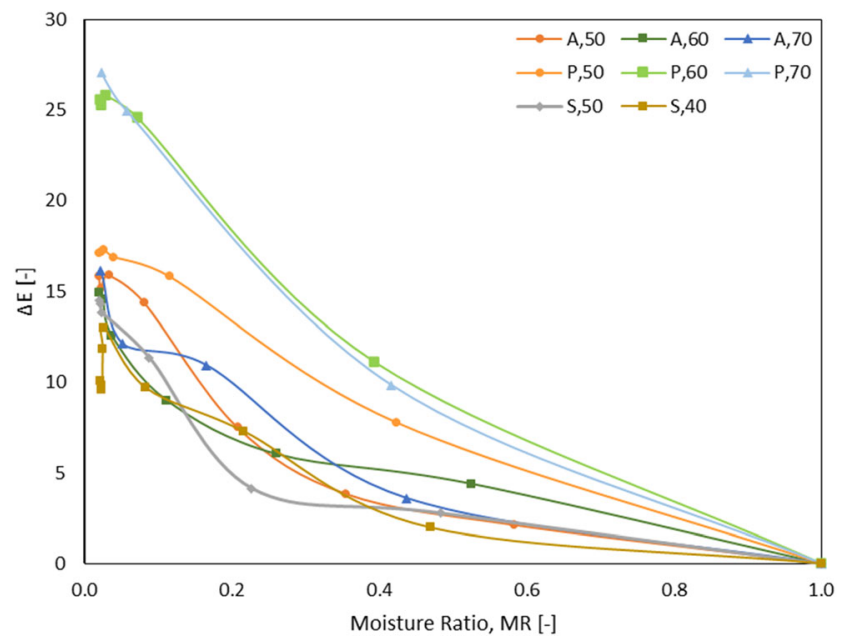

Fig. 12 Total colour change as a function of moisture ratio for different drying strategies at $50{ }^{\circ} \mathrm{C}, 60^{\circ} \mathrm{C}$ and $70^{\circ} \mathrm{C}$ the combined effect of time-temperature significantly affects the total carotenoid loss (Zhao et al., 2014). Figure 14 depicts the total carotenoid retention of the samples as a function of moisture ratio for the three different strategies.

The results obtained for strategy A show that the highest level of TCR is observed at $60^{\circ} \mathrm{C}(\mathrm{TCR}=0.69)$, followed by $50{ }^{\circ} \mathrm{C}(\mathrm{TCR}=0.63)$ and $70{ }^{\circ} \mathrm{C}(\mathrm{TCR}=0.55)$. It is believed that the longer exposure time for $50{ }^{\circ} \mathrm{C}$ and the higher temperature at $70{ }^{\circ} \mathrm{C}$ led to the observed lower level of TCR which is in accordance with the findings of Karabulut et al. (2007). According to Md Saleh et al. (2019), for carrot samples of a thickness of $3 \mathrm{~mm}$, TCR of $0.47,0.66$ and 0.46 was obtained for $50{ }^{\circ} \mathrm{C}, 60{ }^{\circ} \mathrm{C}$ and $70{ }^{\circ} \mathrm{C}$, respectively. The findings from the study mentioned are concurrent to the results obtained for strategy $\mathrm{A}$. The difference in the retention values for $50^{\circ} \mathrm{C}$ and $70^{\circ} \mathrm{C}$ could be due to the use of different dryers with different operation modes for the drying process. Furthermore, the studies were conducted in different years and at different seasons, with that by Md Saleh et al. (2019) conducted during the carrot harvest season (OctoberNovember) and the current study conducted in the off season (January-February) and thus the carrots were stored for a prolonged time.

In the case of strategy $\mathrm{P}$, unlike strategy A, the TCR was observed to be high for all temperatures with values of 0.73 ,

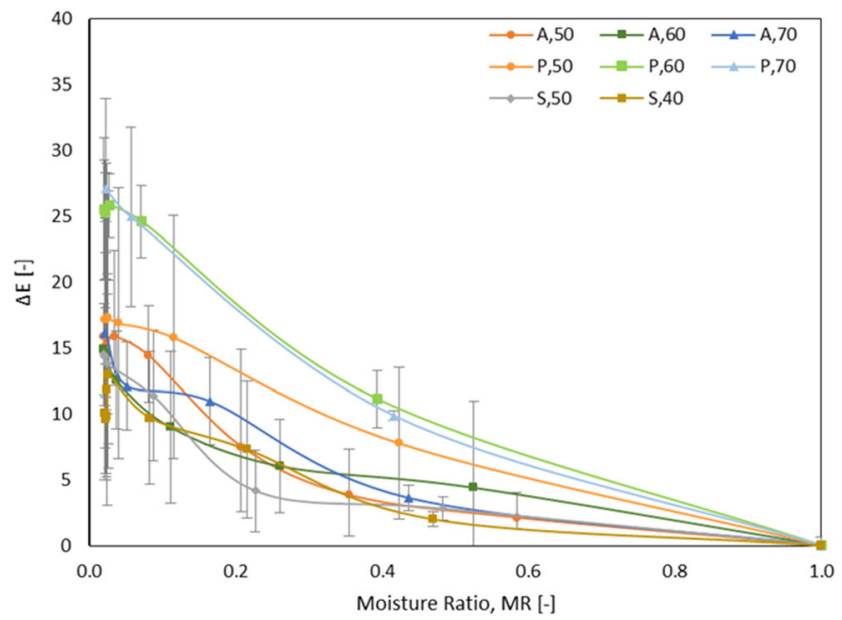

Fig. 13 Total colour change as a function of moisture ratio for different drying strategies at $50^{\circ} \mathrm{C}, 60^{\circ} \mathrm{C}$ and $70{ }^{\circ} \mathrm{C}$ including standard deviations 


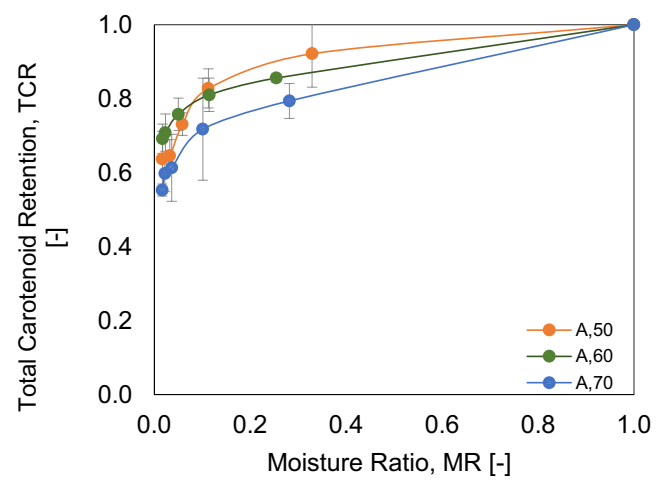

(a)

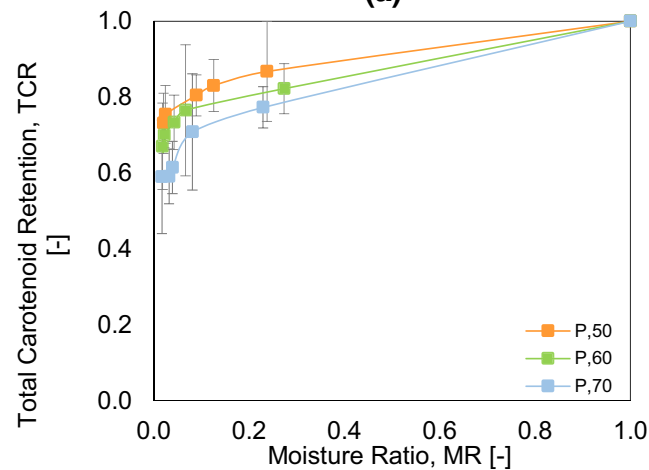

(b)

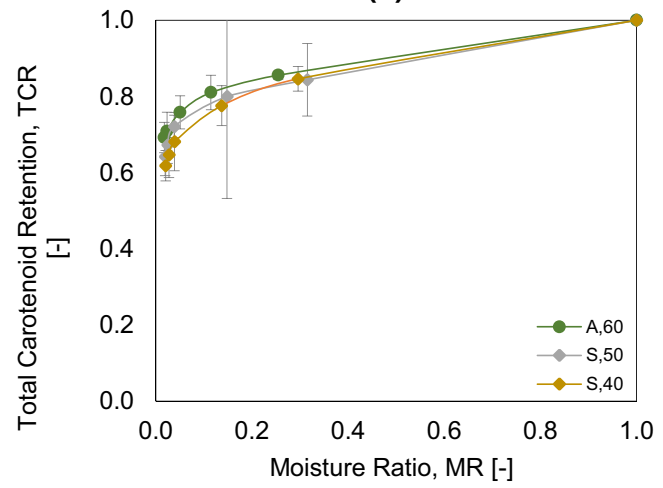

(c)

Fig. 14 Total carotenoid retention vs moisture ratio for three strategies at three different temperatures, a strategy A, b strategy P and $\mathbf{c}$ strategy S50/ S40

0.67 and 0.59 for $50{ }^{\circ} \mathrm{C}, 60{ }^{\circ} \mathrm{C}$ and $70{ }^{\circ} \mathrm{C}$. Furthermore, for strategy $\mathrm{P}$, the TCR was highest for $50^{\circ} \mathrm{C}$ as opposed to $60^{\circ} \mathrm{C}$ in strategy A. A linear trend in the decrease of TCR content as a function of MR is observed for strategy $P$ for all three temperatures indicating this strategy as having a better correlation as compared to strategy A. According to investigation performed by Onwude et al. (2017), pumpkin slices dried at 80 ${ }^{\circ} \mathrm{C}$ had higher TCR content due to the short drying times as compared to slices dried at $50{ }^{\circ} \mathrm{C}$. For strategy $\mathrm{P}$, as mentioned previously, air temperature close to $100{ }^{\circ} \mathrm{C}$ was obtained during the initial drying phase which in turn assisted in decreasing the drying time and thus retaining higher TCR values.
As for strategy S50/S40, it was believed that the TCR content would be similar to or higher than the values obtained for $60{ }^{\circ} \mathrm{C}$ with strategy A. However, the exact opposite trend was observed from the results obtained with final TCR content of 0.64 and 0.61 for S50 and S40, respectively. This could be due to severe cellular damage to the tissues as the samples are exposed to hot air for a longer amount of time as in the case of this strategy (Md Saleh et al., 2019). According to an investigation performed by Karabulut et al. (2007) on the degradation of $\beta$-carotene in apricots, an increase in drying time causes significant degradation of the $\beta$-carotene as compared to increased drying temperatures. In the case of strategy S50/ S40, the samples received constant air temperature of $60^{\circ} \mathrm{C}$ for $80 \mathrm{~min}$ and were further reduced by either $10^{\circ} \mathrm{C}$ or $20^{\circ} \mathrm{C}$ for the rest of the drying period. Even though the overall air temperature the samples were exposed to was lower, it is believed that the longer drying time led to structural damages that affected the total carotenoid content. Md Saleh et al. (2019) also observed accelerated degradation of TCR after the inflection point $(\mathrm{MC} \leq 30 \%)$. A similar trend was also observed within this study wherein until the inflection point, the degradation of TCR was rather slow; however, after the inflection point, a rapid degradation was seen. This phenomenon could be due to the deformation of the structure that in turn led to membrane destruction (Zhang et al., 2017).

Additionally, across all strategies, significant deviations between repetitions at specific MR have also been observed. Carrots are naturally occurring heterogenous products whose physiological conditions, environmental conditions during harvest and storage period affect the nutritional components within the product (Pénicaud et al., 2011), thus also leading to the observed fluctuations between the repetitions.

\section{Correlation of Total Carotenoid Retention to Colour}

Carotenoids, especially $\beta$-carotene pigments, are responsible for the associated colour of the product (Karabulut et al., 2007), and hence, it becomes important to correlate the two parameters so as to understand the degradation of carotenoids as a function of colour change. As different strategies were implemented within the current study, the TCR content was correlated to the colour values from the chromameter rather than those to the camera system so as to allow for comparison with other previous studies such as those conducted by Karabulut et al. (2007), Md Saleh et al. (2019) and Md Saleh et al. (2020).

Figure 15 shows the correlation between the total carotenoid retention and overall colour change for the different drying strategies.

From the results obtained for strategy A and strategy S50/ 40 , the degradation of TCR corresponding to a change in $\Delta E$ values is observed. As the colour degrades, the TCR content also degrades and is in agreement with the findings of Ruiz 
et al. (2005), Koca et al. (2007) and Saxena et al. (2012), who established a linear correlation between TCR and colour changes for apricots, papaya puree and jackfruit, respectively. However, these studies as well as strategy A and strategy S50/ S40 within this study consider constant air temperature as compared to monitoring based on product temperature.

Strategy $\mathrm{P}$ conducted within this study monitors product temperature, and corresponding results obtained are contrary to those from strategy A and S50/S40. On comparing the strategies, maximum colour degradation is observed for strategy P. However, even though the colour degradation values are high, the corresponding TCR content values are either equal to or higher than the TCR values obtained through strategy A or strategy S50/S40. For example, at $50{ }^{\circ} \mathrm{C}$ under strategy $\mathrm{P}, \Delta E$ is equal to 20 which corresponds to a TCR content of about 0.79 . Hence, the presumption of change in colour being a potential indicator of degradation of total carotenoids is rather applicable to conditions under constant air temperature.

\section{Water Activity and Rehydration}

\section{Water Activity}

To sustain a longer shelf life for products, it is necessary to reduce the water activity $\left(a_{\mathrm{w}}\right)$ to safe levels $<0.6$. Due to autocatalytic oxidation, carotenoids undergo rapid degradation even in dried products. In order to maintain the carotenoid levels and reduce the degradation of samples due to microbial spoilage or growth, it is rather suggested to store dehydrated products at a monolayer $a_{\mathrm{w}}$ (Lavelli et al., 2007). Within the current study, by the end of the drying process, the $a_{\mathrm{w}}$ values ranged between 0.23 and 0.35 . According to the investigation performed by Lavelli et al. (2007) and Md Saleh et al. (2019), an $a_{\mathrm{w}}$ range lower than 0.4 indicates minimum enzymatic and non-enzymatic browning and maximum carotenoid stability. Table 9 provides the final water activity for the samples dried at $50{ }^{\circ} \mathrm{C}, 60{ }^{\circ} \mathrm{C}$ and $70{ }^{\circ} \mathrm{C}$ for the respective strategies.

In addition to measuring the final $a_{\mathrm{w}}$ of dried samples, $a_{\mathrm{w}}$ values were also measured at regular intervals during the drying process to understand the effect of the drying strategy on the $a_{\mathrm{w}}$ values.

Figure 16 presents $a_{\mathrm{w}}$ as a function of MR at $50{ }^{\circ} \mathrm{C}, 60^{\circ} \mathrm{C}$ and $70{ }^{\circ} \mathrm{C}$ for the respective drying strategies. The results obtained from plotting the $a_{\mathrm{w}}$ over function MR reveal no effect of strategies on the $a_{\mathrm{w}}$ values during the drying process. Deviation between values are also observed to be within an acceptable range of $\pm 2 \%$ with the exception for the sample at $0.1 \mathrm{MR}$ dried under strategy $\mathrm{A}$ at $70^{\circ} \mathrm{C}$.

\section{Rehydration Ratio}

Table 10 provides an overview of the rehydration ratio (RR) for the samples dried at $50{ }^{\circ} \mathrm{C}, 60{ }^{\circ} \mathrm{C}$ and $70{ }^{\circ} \mathrm{C}$ under respective drying strategies. It is observed that both process strategy and temperature have no significant influence on the RR. An RR of about 0.5 was obtained for strategy A while almost 0.6 was obtained for strategy P and strategy S50/S40 for all temperatures. A higher rehydration ratio indicates less damage to the samples and hence better restoration capability to its original state (Krokida \& Philippopoulos, 2005). Implementation of strategy P and strategy S50/S40 seems to have created less structural damage to the samples as compared to strategy A. Furthermore, RR values for samples dried at $50{ }^{\circ} \mathrm{C}$ are lower than those for samples dried for $60^{\circ} \mathrm{C}$ and $70^{\circ} \mathrm{C}$ independent of the two drying strategies implemented. Similar findings were also observed by Doymaz (2017), wherein independent of the pre-treatment applied, the carrot slices dried at $50{ }^{\circ} \mathrm{C}$
Fig. 15 Total carotenoid retention vs $\Delta E$ for three strategies at varying temperatures (A, P, S50/S40)

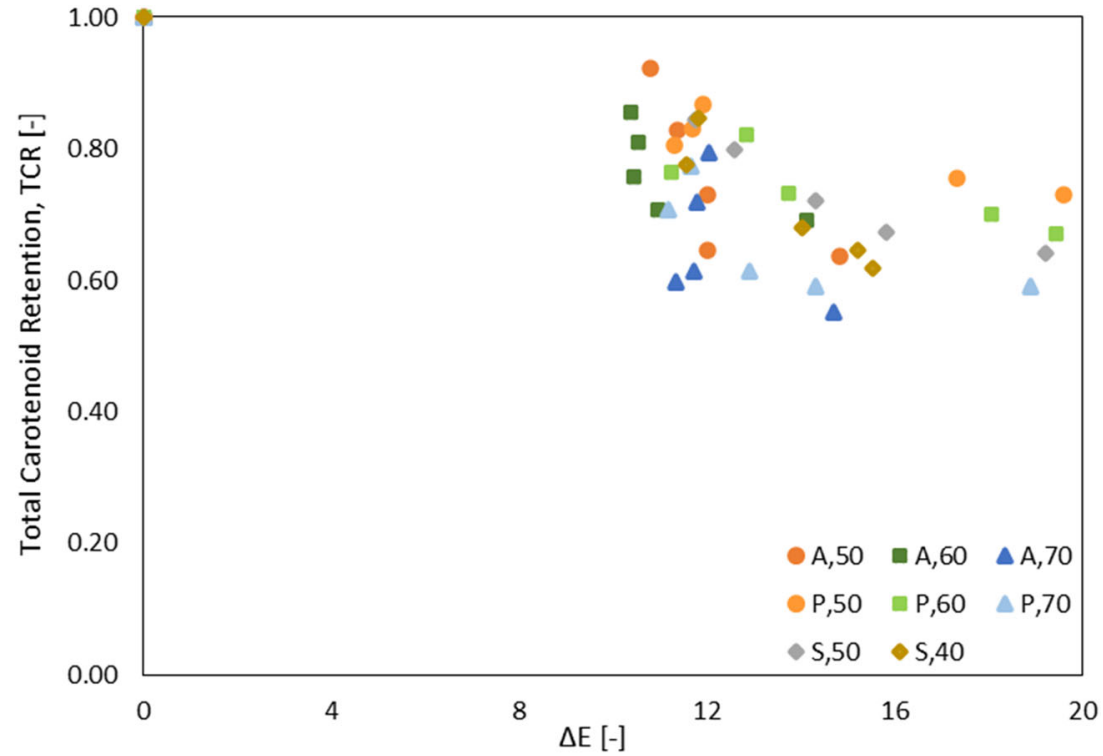


Table 9 Final water activity content of carrots dried under three different strategies at varying temperatures (A, P, S50/S40)

\begin{tabular}{llll}
\hline Water activity, $a_{\mathrm{w}}[-]$ & & & \\
\hline Strategy & $\mathrm{A}$ & $\mathrm{P}$ & $\mathrm{S}$ \\
\hline $50^{\circ} \mathrm{C}$ & 0.359 & 0.315 & \\
$60{ }^{\circ} \mathrm{C}$ & 0.271 & 0.232 & \\
$70^{\circ} \mathrm{C}$ & 0.324 & 0.312 & \\
$60^{\circ} \mathrm{C} \Delta 10^{\circ} \mathrm{C}$ & & & 0.358 \\
$60^{\circ} \mathrm{C} \Delta 20^{\circ} \mathrm{C}$ & & & 0.407 \\
\hline
\end{tabular}

had considerably lower RR values than at $60{ }^{\circ} \mathrm{C}$ or $70{ }^{\circ} \mathrm{C}$. Comparing the results obtained from this study to those of the work conducted by Md Saleh et al. (2019), the authors obtained a rehydration ratio of 0.48 for $3.5 \mathrm{~mm}$ slice thickness for air temperature-controlled samples. Thus, it can be incurred that for 3-mm slices, an RR of about 0.5 for strategy $\mathrm{A}$ is in agreement with the findings.

\section{Energy Consumption}

The specific energy consumption (SEC) values for three different temperatures under respective drying strategies are presented in Fig. 17.

Based on the strategies, for strategy A, in relation to $60^{\circ} \mathrm{C}$, a decrease by $6.8 \%$ for $50^{\circ} \mathrm{C}$ and $25.5 \%$ for $70{ }^{\circ} \mathrm{C}$ was observed in the SEC values. On the other hand, an increase of $19.4 \%$ and $10.2 \%$ in the energy consumption was observed for $50^{\circ} \mathrm{C}$ and $70{ }^{\circ} \mathrm{C}$ for strategy P. A review conducted on the energy consumption by Kumar et al. (2014) reveals significant energy savings with intermittent drying as compared to continuous drying. According to the authors, with increasing tempering period, a decrease in the overall energy saving is

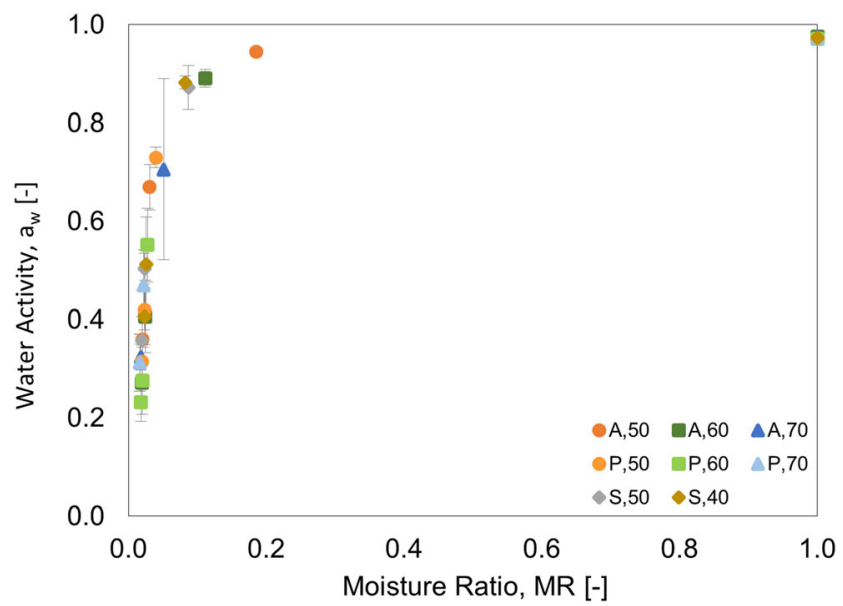

Fig. 16 Water activity over changing moisture ratio for carrot samples dried under three different strategies at varying temperatures (A, P, S50/ S40)
Table 10 Rehydration ratio for different drying strategies

Rehydration ratio [-]

\begin{tabular}{llll}
\hline Strategy & $\mathrm{A}$ & $\mathrm{P}$ & $\mathrm{S}$ \\
\hline $50^{\circ} \mathrm{C}$ & 0.509 & 0.565 & \\
$60^{\circ} \mathrm{C}$ & 0.523 & 0.581 & \\
$70^{\circ} \mathrm{C}$ & 0.538 & 0.597 & \\
$60^{\circ} \mathrm{C} \Delta 10^{\circ} \mathrm{C}$ & & & 0.567 \\
$60{ }^{\circ} \mathrm{C} \Delta 20^{\circ} \mathrm{C}$ & & & 0.556 \\
\hline
\end{tabular}

observed. Even though no tempering was conducted within the current investigation, the stepwise change in the temperature at the inflection point led to a decrease of $9.9 \%$ for S50 and $1.9 \%$ for $\mathrm{S} 40$ when compared to strategy A $\left(60{ }^{\circ} \mathrm{C}\right)$. Comparing based on temperature $70^{\circ} \mathrm{C}$ had the lowest energy consumption followed by $50{ }^{\circ} \mathrm{C}$ and finally $60{ }^{\circ} \mathrm{C}$. Lower energy consumption for higher temperatures is due to the decrease in drying time that compensates for the energy demand. These results are in agreement with the investigation performed by Koyuncu et al. (2007) and Ndisya et al. (2020) wherein the temperature was observed to have a significant effect on the specific energy consumption as an increase in temperature compensates for the corresponding drying time and in turn the high energy demand. Overall, the P strategy had the overall lowest energy consumption. It was presumed that $\mathrm{S} 50 / \mathrm{S} 40$ would ideally have a much lower energy consumption; however, the longer drying times required to reach the desired MR led to the associated high SEC values.

\section{General Discussion}

The present study analysed the effects of three different drying strategies, namely air temperature controlled (strategy A) at 50 ${ }^{\circ} \mathrm{C}, 60^{\circ} \mathrm{C}$ and $70^{\circ} \mathrm{C}$; product temperature controlled (strategy P) at $50{ }^{\circ} \mathrm{C}, 60^{\circ} \mathrm{C}$ and $70{ }^{\circ} \mathrm{C}$; and stepwise strategy (S50/S40) at $60{ }^{\circ} \mathrm{C}$ on drying behaviour, colour change, total carotenoid retention, water activity, rehydration ratio and energy consumption using non-invasive measurement techniques.

For the drying behaviour, independent of the strategy implemented, the transition from one drying phase to the next phase can clearly be detected through the product temperature profile, thus indicating the need and necessity of monitoring and controlling the product temperature during drying in order to optimise the process. Furthermore, comparing the different strategies, it was observed that controlling the drying process based on product temperature (strategy $\mathrm{P}$ ) rather than on air temperature led to significantly shorter drying times and is in agreement with the findings of Sturm et al. (2014) and Bantle et al. (2019). Modelling the drying curves indicated that the 
Fig. 17 Specific energy consumption in $\mathrm{MJ} / \mathrm{kg}$ for $50{ }^{\circ} \mathrm{C}$, $60{ }^{\circ} \mathrm{C}$ and $70{ }^{\circ} \mathrm{C}$ under three different strategies (A, P, S50/S40)

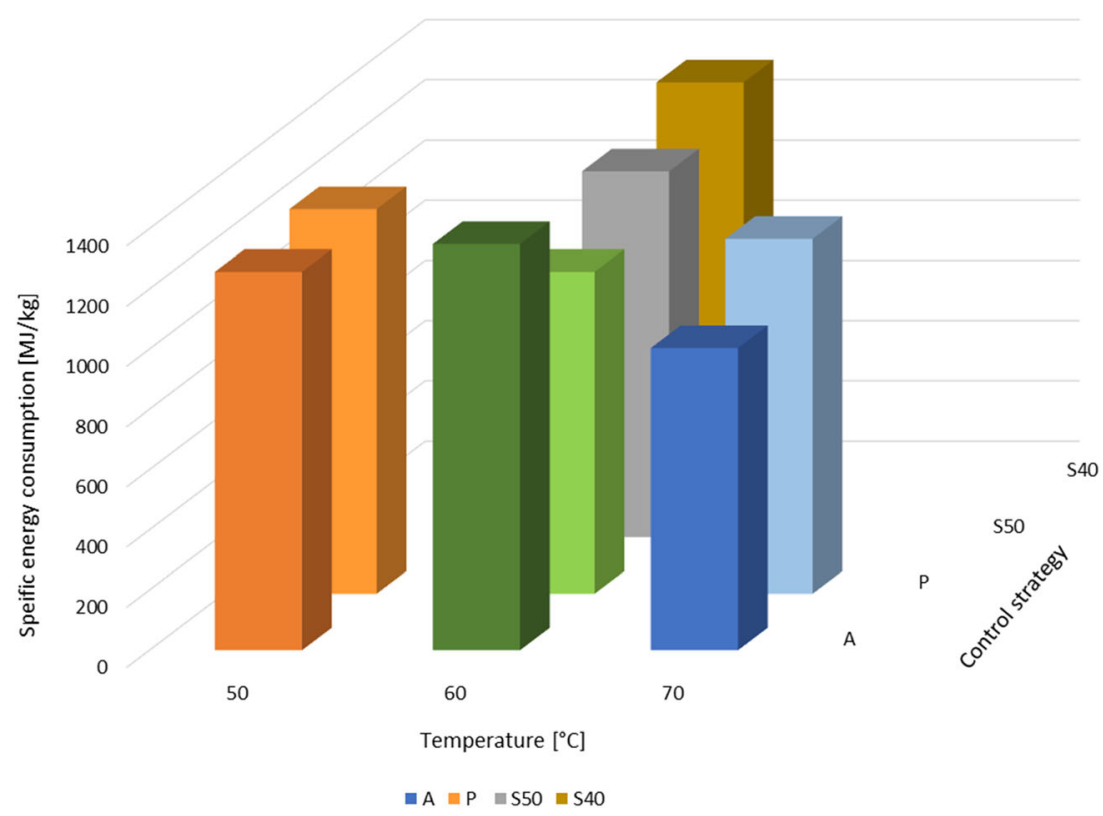

Page model is a good fit under all conditions with an $R^{2}$ adj of 0.99 and RMSE of about 0.01 for all three strategies and the corresponding temperatures.

In terms of colour changes, maximum degradation was observed in the case of strategy $\mathrm{P}$ and minimum in the case of strategy A. This was largely due to the high air temperature in strategy $\mathrm{P}$ during the initial drying phase. Furthermore, shrinkage of the sample also played an important role in the colour measurement and analysis especially in the case of S40 samples. The overall trend in colour degradation is in line with the investigations performed by Saxena et al. (2012), Chen and Martynenko (2013), Doymaz and Özdemir (2014) and Md Saleh et al. (2019). The experiments performed show promising results for non-invasive inline measurement of process and product characteristics through implementation of an RGB camera system. The correlation between the noninvasive and the invasive measurement techniques shows that the use of an RGB camera system has allowed for analysis of a greater number of samples as well as analysis of the whole area of the samples in focus, thus leading to better results.

The total carotenoid retention was also observed to be highest for strategy $\mathrm{P}$ followed by strategy S50/S40 and finally strategy A. Based on the studies performed by Chua et al. (2000) and Md Saleh et al. (2020), it was believed that colour change can be used as an indicator for carotenoid degradation. Investigations performed within this study agree partially as contrary results were obtained from strategy P. Furthermore, based on the investigations conducted by $\mathrm{Md}$ Saleh et al. (2019), it was hypothesised that lowering the temperature at the inflection point would positively influence the total carotenoid retention. However, contradicting results were obtained with S50/S40 samples having almost similar values to strategy A. Thus, indicating that in order to significantly retain the carotenoid content after the inflection point, a tempering period like that conducted by Md Saleh et al. (2020) is imminent and a reduction of temperature during the drying process is insufficient.

As for the overall theoretical energy consumption, high values were observed across all strategies. A single-layer research dryer with operating temperature up to $100{ }^{\circ} \mathrm{C}$ for strategy $\mathrm{P}$ and up to $70{ }^{\circ} \mathrm{C}$ for strategy A was used. The purpose of the study was not to deliver accurate measurements of energy consumption or to optimise the energetic performance of the dryer employed but to provide a controlled drying regime for the comparison of process settings and strategies. Thus, a theoretical approach for estimation of energy consumption was applied to facilitate the comparison between different strategies in qualitative rather than quantitative terms. The results obtained show that stepwise drying does reduce energy consumption in comparison to constant air temperature. However, the results reveal that product temperature-controlled drying (strategy P) is key for overall energy savings.

\section{Conclusions}

In conclusion, based on the results obtained through extensive experimental investigation and data analysis, it can be incurred that the product temperature strategy is advantageous as compared to the other strategies to not only minimise drying time but also ensure optimum product quality and process efficiency. Furthermore, use of non-invasive measurement techniques such as RGB and infrared camera is a sophisticated technique for control and monitoring of product quality and for providing further insight in product changes during the 
drying process. Future work for real-time measurement of colour analysis in combination with control and measurement systems is required. Further investigation with varying slice thicknesses and process strategies needs to be considered in the future.

Author Contribution Conceptualization, B.S., S.R.; methodology, S.R., P.K., R.S., B.S.; software, S.R.,B.K.; formal analysis, all; investigation, S.R., P.K., R.S.; resources, B.S., O.H.; data curation, S.R., P.K., B.S.; writing - original draft preparation, S.R., P.K., B.S.; writing — review and editing, all; visualisation, S.R., B.S.; supervision, B.S., O.H.; project administration, B.S.,S.R.,O.H; funding acquisition, B.S., O.H.

Funding Open Access funding enabled and organized by Projekt DEAL. The authors acknowledge the UPGRADE Plus (Project number: BLE 2816PROC01) and SusOrgPlus Project (Project number: BLE 2817OE005) for their financial support for this work. The UPGRADE Plus project and the SusOrgPlus project are supported by funds of the Federal Ministry of Food and Agriculture (BMEL) based on a decision of the Parliament of the Federal Republic of Germany via the Federal Office for Agriculture and Food (BLE). The SusOrgPlus project is also a part of the CORE Organic Cofund and the cofund from the European Commission.

\section{Declarations}

Conflict of Interest The authors declare no competing interests.

Open Access This article is licensed under a Creative Commons Attribution 4.0 International License, which permits use, sharing, adaptation, distribution and reproduction in any medium or format, as long as you give appropriate credit to the original author(s) and the source, provide a link to the Creative Commons licence, and indicate if changes were made. The images or other third party material in this article are included in the article's Creative Commons licence, unless indicated otherwise in a credit line to the material. If material is not included in the article's Creative Commons licence and your intended use is not permitted by statutory regulation or exceeds the permitted use, you will need to obtain permission directly from the copyright holder. To view a copy of this licence, visit http://creativecommons.org/licenses/by/4.0/.

\section{References}

Aghbashlo, M., Kianmehr, M. H., \& Samimi-Akhijahani, H. (2008). Influence of drying conditions on the effective moisture diffusivity, energy of activation and energy consumption during the thin-layer drying of berberis fruit (Berberidaceae). Energy Conversion and Management, 49(10), 2865-2871. https://doi.org/10.1016/j. enconman.2008.03.009

Agrawal, Y. C., \& Singh, R. P. (1977). Thin-layer drying studies on short-grain rough rice. ASAE Paper No. 77-3531, ASAE, St Joseph, MI.

Akoy, E. (2014). 27 IFRJ 21 (05) 2014 Elamin 086. International Food Research Journal, 21(5), 1911-1914.

AOAC International (AOAC). (2016). Official methods of analysis of $A O A C$ International (20th ed.). Rockville, MD: AOAC International.

Awuah, G. B., Ramaswamy, H. S., \& Economides, A. (2007). Thermal processing and quality: principles and overview. Chemical
Engineering and Processing: Process Intensification, 46(6), 584602. https://doi.org/10.1016/j.cep.2006.08.004 .

Ayensu, A. (1997). Dehydration of food crops using a solar dryer with convective heat flow. Solar Energy, 59(4-6), 121-126. https://doi. org/10.1016/S0038-092X(96)00130-2 .

Bantle, M., Kopp, C., \& Claussen, I. C. (2019). Improved process control by surface temperature-controlled drying on the example of sweet potatoes. In Proceeding of Eurodrying 2019, 7th European Drying Conference, July 10-12, 2019, Torino, Italy.

Burnham, K. P. (2002). Model selection and multimodel inference: a practical information-theoretic approach (2nd ed.). Secaucus, New York, NY: Springer-Verlag New York, Incorporated.

Chen, Y., \& Martynenko, A. (2013). Computer vision for real-time measurements of shrinkage and color changes in blueberry convective drying. Drying Technology, 31(10), 1114-1123. https://doi.org/10. 1080/07373937.2013.775587.

Chin, S. K., \& Law, C. L. (2010). Product quality and drying characteristics of intermittent heat pump drying of Ganoderma tsugae Murrill. Drying Technology, 28(12), 1457-1465. https://doi.org/10.1080/ 07373937.2010.482707.

Chua, K. J., Mujumdar, A. S., Chou, S. K., Hawlader, M., \& Ho, J. C. (2000). Convective drying of banana, guava and potato pieces: Effect of cyclical variations of air temperature on drying kinetics and color change. Drying Technology, 18(4-5), 907-936. https:// doi.org/10.1080/07373930008917744.

Chua, K. J., Mujumdar, A. S., Hawlader, M., Chou, S. K., \& Ho, J. C. (2001a). Batch drying of banana pieces - effect of stepwise change in drying air temperature on drying kinetics and product colour. Food Research International, 34(8), 721-731. https://doi.org/10. 1016/S0963-9969(01)00094-1 .

Chua, K. J., Mujumdar, A. S., Hawlader, M. N. A., Chou, S. K., \& Ho, J. C. (2001b). Convective drying of agricultural products. Effect of continuous and stepwise change in drying air temperature. Drying Technology, 19(8), 1949-1960. https://doi.org/10.1081/DRT100107282 .

Chua, K. J., Hawlader, M. N. A., Chou, S. K., \& Ho, J. C. (2002). On the study of time-varying temperature drying - effect on drying kinetics and product quality. Drying Technology, 20(8), 1559-1577. https:// doi.org/10.1081/DRT-120014052 .

Crichton, S., Shrestha, L., Hurlbert, A., \& Sturm, B. (2018). Use of hyperspectral imaging for the prediction of moisture content and chromaticity of raw and pretreated apple slices during convection drying. Drying Technology, 36(7), 804-816. https://doi.org/10. 1080/07373937.2017.1356847.

Davidson, V. J., Li, X., \& Brown, R. B. (2004). Forced-air drying of ginseng root: 1. Effects of air temperature on quality. Journal of Food Engineering, 63(4), 361-367. https://doi.org/10.1016/j. jfoodeng.2003.08.014 .

Demiray, E., \& Tulek, Y. (2017). Degradation kinetics of $\beta$-carotene in carrot slices during convective drying. International Journal of Food Properties, 20(1), 151-156. https://doi.org/10.1080/ 10942912.2016.1147460.

Diamante, L. M., \& Munro, P. A. (1993). Mathematical modelling of the thin layer solar drying of sweet potato slices. Solar Energy, 51(4), 271-276. https://doi.org/10.1016/0038-092X(93)90122-5 .

Doymaz, I. (2004). Convective air drying characteristics of thin layer carrots. Journal of Food Engineering, 61(3), 359-364. https://doi. org/10.1016/S0260-8774(03)00142-0 .

Doymaz, İ. (2017). Drying kinetics, rehydration and colour characteristics of convective hot-air drying of carrot slices. Heat and Mass Transfer, 53(1), 25-35. https://doi.org/10.1007/s00231-016-17918 .

Doymaz, İ., \& Özdemir, Ö. (2014). Effect of air temperature, slice thickness and pretreatment on drying and rehydration of tomato. International Journal of Food Science \& Technology, 49(2), 558564. https://doi.org/10.1111/ijfs.12337 . 
Earle, R. L. (1983). Unit operations in food processing, 2nd edition. Pergamon Press.

Eim, V. S., Urrea, D., Rosselló, C., García-Pérez, J. V., Femenia, A., \& Simal, S. (2013). Optimization of the drying process of carrot (Daucus carota v. Nantes) on the basis of quality criteria. Drying Technology, 31(8), 951-962.

FAOSTAT. (2020). Comparison of World crops production quantities 2018. Food and Agriculture Organization Corporate Statistical Database. Available online at http://www.fao.org/faostat/en/\# compare, updated on $2 / 18 / 2020$, checked on $5 / 18 / 2020$.

Frias, J., Peñas, E., Ullate, M., \& Vidal-Valverde, C. (2010). Influence of drying by convective air dryer or power ultrasound on the vitamin $\mathrm{C}$ and $\beta$-carotene content of carrots. Journal of agricultural and food chemistry, 58(19), 10539-10544. https://doi.org/10.1021/jf102797y .

von Gersdorff, G. J. E., Porley, V. E., Retz, S. K., Hensel, O., Crichton, S. O. J., \& Sturm, B. (2017). Drying behavior and quality parameters of dried beef (biltong) subjected to different pre-treatments and maturation stages. Drying Technology, 36(1), 21-32. https://doi.org/10. 1080/07373937.2017.1295979 .

Ghoshdastidar, P. S. (2018). 4.30 Heat transfer in rotary kilns. In R. P. Chhabra (Ed.), CRC handbook of thermal engineering (2nd ed., pp. 1338-1351). Boca Raton, London, New York: CRC Press Taylor \& Francis Group.

Henderson, S. M., \& Pabis, S. (1961). Grain drying theory: temperature effect on drying coefficient. Journal of Agricultural Engineering Research, 6, 169-174.

Huang, H., Liu, L., \& Ngadi, M. O. (2014). Recent developments in hyperspectral imaging for assessment of food quality and safety. Sensors (Basel, Switzerland), doi: https://doi.org/10.3390/ s140407248, 14, 4, 7248, 7276.

Karabulut, I., Topcu, A., Duran, A., Turan, S., \& Ozturk, B. (2007). Effect of hot air drying and sun drying on color values and $\beta$ carotene content of apricot (Prunus armenica L.). LWT - Food Science and Technology. https://doi.org/10.1016/j.lwt.2006.05.001 .

Karam, M. C., Petit, J., Zimmer, D., Baudelaire Djantou, E., \& Scher, J. (2016). Effects of drying and grinding in production of fruit and vegetable powders: a review. Journal of Food Engineering, 188, 32-49. https://doi.org/10.1016/j.jfoodeng.2016.05.001 .

Kerdpiboon, S., Devahastin, S., \& Kerr, W. L. (2007). Comparative fractal characterization of physical changes of different food products during drying. Journal of Food Engineering, 83(4), 570-580. https://doi.org/10.1016/j.jfoodeng.2007.03.039.

Kluyver, T., Ragan-Kelley, B., Pérez, F., Granger, B. E., Bussonnier, M., Frederic, J., et al. (2016). Jupyter Notebooks - a publishing format for reproducible computational workflows. In Positioning and power in academic publishing: players, agents and agendas: proceedings of the 20th International Conference on Electronic Publishing (pp. 87-90). Amsterdam, Netherlands: IOS Press.

Koca, N., Burdurlu, H. S., \& Karadeniz, F. (2007). Kinetics of colour changes in dehydrated carrots. Journal of Food Engineering, 78(2), 449-455.

Koyuncu, T., Pinar, Y., \& Lule, F. (2007). Convective drying characteristics of azarole red (Crataegus monogyna Jacq.) and yellow (Crataegus aronia Bosc.) fruits. Journal of Food Engineering. https://doi.org/10.1016/j.jfoodeng.2005.09.036 .

Krokida, M., \& Marinos-Kouris, D. (2003). Rehydration kinetics of dehydrated products. Journal of Food Engineering, 57(1), 1-7. https://doi.org/10.1016/S0260-8774(02)00214-5 .

Krokida, M., \& Philippopoulos, C. (2005). Rehydration of dehydrated foods. Drying Technology, 23(4), 799-830. https://doi.org/10.1081/ DRT-200054201 .

Kumar, C., Karim, M. A., \& Joardder, M. U. (2014). Intermittent drying of food products: a critical review. Journal of Food Engineering, 121, 48-57. https://doi.org/10.1016/j.jfoodeng.2013.08.014

Lavelli, V., Zanoni, B., \& Zaniboni, A. (2007). Effect of water activity on carotenoid degradation in dehydrated carrots. Food chemistry,
104(4), 1705-1711. https://doi.org/10.1016/j.foodchem.2007.03. 033 .

Lewicki, P. P. (1998). Some remarks on rehydration of dried foods. Journal of Food Engineering, 36(1), 81-87. https://doi.org/10. 1016/S0260-8774(98)00022-3 .

Lin, T. M., Durance, D., \& T., \& Scaman, C. H. (1998). Characterization of vacuum microwave, air and freeze dried carrot slices. Food Research International, 31(2), 111-117. https://doi.org/10.1016/ S0963-9969(98)00070-2 .

Mahiuddin, M., Khan, M. I. H., Kumar, C., Rahman, M. M., \& Karim, M. A. (2018). Shrinkage of food materials during drying: current status and challenges. Comprehensive Reviews in Food Science and Food Safety, 17(5), 1113-1126. https://doi.org/10.1111/1541-4337. 12375 .

Markowski, M., Stankiewicz, I., Zapotoczny, P., \& Borowska, J. (2006). Effect of variety on drying characteristics and selected quality attributes of dried carrots. Drying Technology, 24(8), 1011-1018. https://doi.org/10.1080/07373930600776191 .

Martin, A. (2015). Chapter 4. Colour management in the graphic technologies. In graphic communication open textbook collective (Ed.) Graphic design and print production Fundamentals. Victoria B.C, 84-125.

Martynenko, A. (2006). Computer-vision system for control of drying processes. Drying Technology, 24(7), 879-888. https://doi.org/10. 1080/07373930600734067.

Martynenko, A. \& Chen, Y. (2013). Real-time quality evaluation in fruit drying, using computer vision. In Proceedings of 2013 CIGR Section VII International Technical Symposium. Guangzhou, 3-7 November 2013.

Martynenko, A., \& Kudra, T. (2015). Non-isothermal drying of medicinal plants. Drying Technology, 33(13), 1550-1559. https://doi.org/10. 1080/07373937.2015.1010209.

McKinney, W. (2010). Data structures for statistical computing in python. In Proceedings of the 9th Python in Science Conference (445), 56-61

Md Saleh, R., Kulig, B., Hensel, O., \& Sturm, B. (2019). Investigation of dynamic quality changes and optimization of drying parameters of carrots (Daucus carota var. laguna). Journal of Food Process Engineering. https://doi.org/10.1111/jfpe.13314

Md Saleh, R., Kulig, B., Emiliozzi, A., Hensel, O., Sturm, B. (2020). Impact of critical control-point based intermittent drying on drying kinetics and quality of carrot (Daucus carota var. laguna). Thermal Science and Engineering Progress, 20. https://doi.org/10.1016/j. tsep.2020.100682.

Motevali, A., Minaei, S., \& Khoshtagaza, M. H. (2011). Evaluation of energy consumption in different drying methods. Energy Conversion and Management, 52(2), 1192-1199. https://doi.org/ 10.1016/j.enconman.2010.09.014 .

Mujumdar, A. S. (2006). Handbook of industrial drying (3rd ed.). Boca Raton: Taylor \& Francis a CRC title part of the Taylor \& Francis imprint a member of the Taylor \& Francis Group the academic division of T\&F Informa plc.

Mujumdar, A. S. (2007). An overview of innovation in industrial drying: current status and R\&D needs. Transport in Porous Media, 66(1-2), 3-18. https://doi.org/10.1007/S11242-006-9018-Y .

Mujumdar, A. S. (Ed.). (2015). Handbook of industrial drying (4th edn). Boca Raton, Fla.: CRC Press.

Mulet, A., Berna, A., Borr, M., Pinaga, F. (1987). Effect of air flow rate on carrot drying. Drying Technology, 5(2), 245-258. https://doi.org/ 10.1080/07373938908916620.

Nasirahmadi, A., \& Behroozi-Khazaei, N. (2013). Identification of bean varieties according to color features using artificial neural network. Spanish Journal of Agricultural Research, 11(3), 670. https://doi. org/10.5424/sjar/2013113-3942 .

Ndisya, J., Mbuge, D., Kulig, B., Gitau, A., Hensel, O., \& Sturm, B. (2020). Hot air drying of purple-speckled Cocoyam (Colocasia 
esculenta (L.) Schott) slices: optimisation of drying conditions for improved product quality and energy savings. Thermal Science and Engineering Progress. https://doi.org/10.1016/j.tsep.2020.100557 .

Nicolaï, B. M., Defraeye, T., de Ketelaere, B., Herremans, E., Hertog, M. L. A. T. M., Saeys, W., Torricelli, A., Vandendriessche, T., \& Verboven, P. (2014). Nondestructive measurement of fruit and vegetable quality. Annual review of food science and technology, 5(1), 285-312. https://doi.org/10.1146/annurev-food-030713-092410 .

Nuñez Vega, A.-M., Sturm, B., \& Hofacker, W. (2016). Simulation of the convective drying process with automatic control of surface temperature. Journal of Food Engineering, 170, 16-23. https://doi.org/10. 1016/j.jfoodeng.2015.08.033 .

Onwude, D. I., Hashim, N., Janius, R., Nawi, N. M., \& Abdan, K. (2017). Color change kinetics and total carotenoid content of pumpkin as affected by drying temperature. Italian Journal of Food Science. https://doi.org/10.14674/1120-1770/ijfs.v398 .

Pan, Y. K., Zhao, L. J., \& Hu, W. B. (1998). The effect of temperingintermittent drying on quality and energy of plant materials. Drying Technology, 17(9), 1795-1812. https://doi.org/10.1080/ 07373939908917653

Pénicaud, C., Achir, N., Dhuique-Mayer, C., Dornier, M., \& Bohuon, P. (2011). Degradation of $\beta$-carotene during fruit and vegetable processing or storage: reaction mechanisms and kinetic aspects: a review. Fruits, 66(6), 417-440. https://doi.org/10.1051/fruits/ 2011058

Perez, F., \& Granger, B. E. (2007). IPython: a system for interactive scientific computing. Computing in Science \& Engineering, 9(3), 21-29. https://doi.org/10.1109/MCSE.2007.53 .

Ratti, C. (Ed.) (2009). Advances in food dehydration. Boca Raton, FL: CRC Press Taylor \& Francis Group (Contemporary Food Engineering).

Ruiz, D., Egea, J., Tomás-Barberán, F. A., \& Gil, M. I. (2005). Carotenoids from new apricot (Prunus armeniaca L.) varieties and their relationship with flesh and skin color. Journal of agricultural and food chemistry. https://doi.org/10.1021/jf0480703 .

Sacilik, K., \& Elicin, A. K. (2006). The thin layer drying characteristics of organic apple slices. Journal of Food Engineering, 73(3), 281-289. https://doi.org/10.1016/j.jfoodeng.2005.03.024 .

Saxena, A., Maity, T., Raju, P. S., \& Bawa, A. S. (2012). Degradation kinetics of colour and total carotenoids in jackfruit (Artocarpus heterophyllus) bulb slices during hot air drying. Food and Bioprocess Technology, 5(2), 672-679. https://doi.org/10.1007/ s11947-010-0409-2.

Shrestha, L., Crichton, S. O., Kulig, B., Kiesel, B., Hensel, O., \& Sturm, B. (2020). Comparative analysis of methods and model prediction performance evaluation for continuous online non-invasive quality assessment during drying of apples from two cultivars. Thermal Science and Engineering Progress, 18, 100461. https://doi.org/10. 1016/j.tsep.2019.100461

Sturm, B. (2010). Einfluss der Führung des Trocknungsprozesses auf den Trocknungsverlauf und die Produkteigenschaften empfindlicher biologischer Güter. Dissertation. Universität Kassel, Witzenhausen.
Sturm, B. (2018). Systemic optimisation and design approach for thermal food processes: Increase of quality, process- and resource efficiency in dried agricultural products manufacturing. Habilitationsschrift. Witzenhausen: Universität Kassel.

Sturm, B., \& Hensel, O. (2017). Pigments and nutrients during vegetable drying processes, dried products storage and their associated colour changes. In Handbook of drying of vegetables and vegetable products (pp. 257-277). Boca Raton: CRC Press Taylor \& Francis Group.

Sturm, B., Hofacker, W., \& Hensel, O. (2009). Automatic control of the drying process of biological materials using optical sensors to acquire surface temperature, color and shape, In American Society of Agricultural and Biological Engineers Annual International Meeting 2009. Proceedings, vol. 5. Reno, Nevada, June 21 June 24. 10 volumes: American Society of Agricultural and Biological Engineers (ASABE), 3032-3041. https://doi.org/10. 13031/2013.27087.

Sturm, B., Nunez Vega, A.-M., \& Hofacker, W. (2014). Influence of process control strategies on drying kinetics, colour and shrinkage of air dried apples. Applied Thermal Engineering, 62(2), 455-460. https://doi.org/10.1016/j.applthermaleng.2013.09.056 .

Sturm, B., Raut, S., Kulig, B., Münsterer, J., Kammhuber, K., Hensel, O., \& Crichton, S. O. J. (2020). In-process investigation of the dynamics in drying behavior and quality development of hops using visual and environmental sensors combined with chemometrics. Computers and Electronics in Agriculture, 175, 105547. https://doi.org/10. 1016/j.compag.2020.105547 .

Tsotsas, E., Mujumdar, A. S. (2007-2014). Modern drying technology. 5 volumes. Weinheim, Chichester: Wiley-VCH.

Velescu, I. D., Tenu, I., CARLESCU, P., \& DOBRE, V. (2013). Convective air drying characteristics for thin layer carrots. Bulletin of University of Agricultural Sciences and Veterinary Medicine Cluj-Napoca. Food Science and Technology. https://doi.org/10. 15835/buasvmen-fst:9619.

van der Walt, S., Colbert, S. C., \& Varoquaux, G. (2011). The NumPy Array: a structure for efficient numerical computation. Computing in Science \& Engineering, 13(2), 22-30. https://doi.org/10.1109/ MCSE.2011.37

Zhang, Z., Wang, X., Li, Y., Wei, Q., Liu, C., Nie, M., Li, D., Xiao, Y., Liu, C., Xu, L., Zhang, M., \& Jiang, N. (2017). Evaluation of the impact of food matrix change on the in vitro bioaccessibility of carotenoids in pumpkin (Cucurbita moschata) slices during two drying processes. Food \& function, 8(12), 4693-4702. https://doi.org/ $10.1039 / \mathrm{c} 7 \mathrm{fo} 01382 \mathrm{e}$.

Zhao, D., An, K., Ding, S., Liu, L., Xu, Z., \& Wang, Z. (2014). Two-stage intermittent microwave coupled with hot-air drying of carrot slices: drying kinetics and physical quality. Food and Bioprocess Technology, 7(8), 2308-2318. https://doi.org/10.1007/s11947-0141274- .

Publisher's Note Springer Nature remains neutral with regard to jurisdictional claims in published maps and institutional affiliations. 